\title{
Engineering Chirally Blind Protein Pseudocapsids into Antibacterial Persisters
}

Ibolya E. Kepiro, ${ }^{\dagger, \bigcirc \odot ~ I r e n e ~ M a r z u o l i, ~}{ }^{\dagger, \ddagger}, \bigcirc \odot$ Katharine Hammond, ${ }^{\dagger, \S, \| \odot ~ X i a o l i a n g ~ B a, ~}{ }^{\perp \odot}$ Helen Lewis, ${ }^{\dagger \oplus 0}$

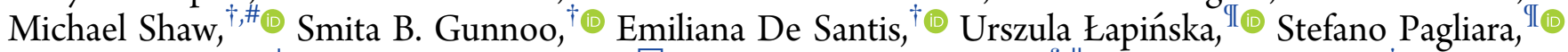

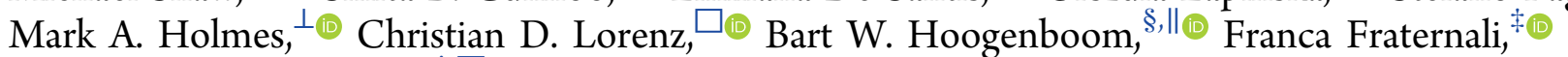
and Maxim G. Ryadnov* ${ }^{*}, \square$ (1)

\author{
${ }^{\dagger}$ National Physical Laboratory, Hampton Road, Teddington, TW11 0LW, U.K. \\ ${ }^{\ddagger}$ Randall Centre for Cell and Molecular Biophysics, King's College London, London, SE1 1UL, U.K. \\ ${ }^{\S}$ Department of Physics and Astronomy, University College London, London, WC1E 6BT, U.K. \\ "London Centre for Nanotechnology, University College London, London, WC1H 0AH, U.K. \\ ${ }^{\perp}$ Department of Veterinary Medicine, University of Cambridge, Cambridge, CB3 OES, U.K. \\ \#Department of Computer Science, University College London, London, WC1 6BT, U.K. \\ ${ }^{I}$ Living Systems Institute, University of Exeter, Exeter, EX4 4QD, U.K. \\ $\square$ Department of Physics, King's College London, Strand Lane, London, WC2R 2LS, U.K.
}

\section{Supporting Information}

ABSTRACT: Antimicrobial resistance stimulates the search for antimicrobial forms that may be less subject to acquired resistance. Here we report a conceptual design of protein pseudocapsids exhibiting a broad spectrum of antimicrobial activities. Unlike conventional antibiotics, these agents are effective against phenotypic bacterial variants, while clearing "superbugs" in vivo without toxicity. The design adopts an icosahedral architecture that is polymorphic in size, but not in shape, and that is available in both $\mathrm{L}$ and $\mathrm{D}$ epimeric forms. Using a combination of nanoscale and single-cell imaging we demonstrate that such
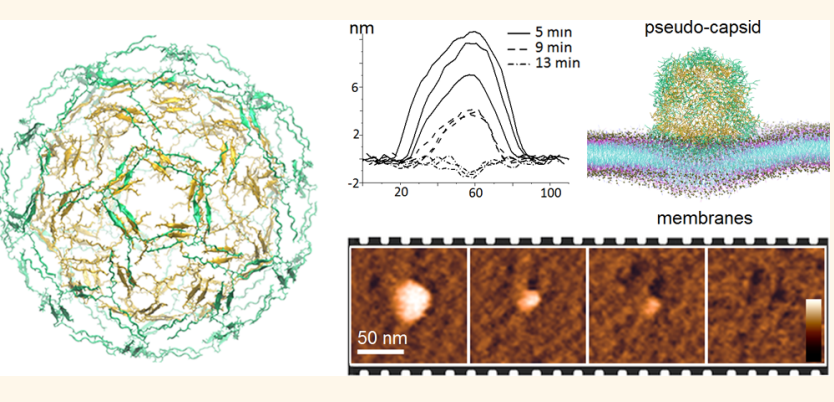
pseudocapsids inflict rapid and irreparable damage to bacterial cells. In phospholipid membranes they rapidly convert into nanopores, which remain confined to the binding positions of individual pseudocapsids. This mechanism ensures precisely delivered influxes of high antimicrobial doses, rendering the design a versatile platform for engineering structurally diverse and functionally persistent antimicrobial agents.

KEYWORDS: protein design, antimicrobial resistance, artificial pseudocapsids, persister cells, superbugs, nanopores

W ith conventional antibiotics losing effectivity at an alarming rate, ${ }^{1}$ antimicrobial resistance represents a major health threat. ${ }^{2}$ This challenge stimulates the search for more effective antimicrobial forms that may be different from traditional antibiotics altogether. ${ }^{3}$ Most antibiotics act by binding to individual intracellular targets in bacterial cells. A single genetic event is enough for bacteria to acquire resistance. ${ }^{3}$ As a consequence, bacteria develop into "superbugs", strains that no longer respond to antibiotic treatments. The spread of these pathogens can be counteracted by antimicrobials tackling a bacterial cell as a whole, thus demonstrating potential to kill growing, persister, and dormant cells, the feat that is inaccessible to conventional antibiotics. ${ }^{4}$ The innate immune systems of multicellular organisms do not use antibiotics. Instead, they deploy host-defense effector molecules to the sites of infection. These molecules are standalone peptides or relatively small domains in globular proteins that recognize microbial surfaces. ${ }^{5}$ These molecules are diverse in structure and origin but share common physicochemical properties. Most of them are cationic and fold into amphipathic conformations upon binding to anionic microbial membranes. ${ }^{6}$ In membranes, these conformations assemble into higher-order oligomers that overcome a threshold of peptide concentration, beyond which antimicrobial effects become apparent. ${ }^{7}$ This is more characteristic of host-defense peptides $^{8}$ than of effector domains of multifunctional proteins

Received: August 27, 2019

Accepted: December 3, 2019

Published: December 3, 2019 


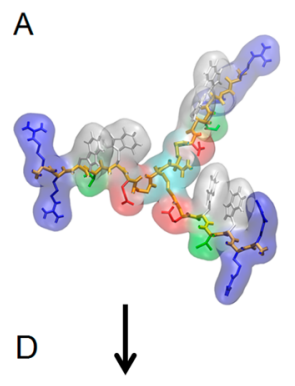

B
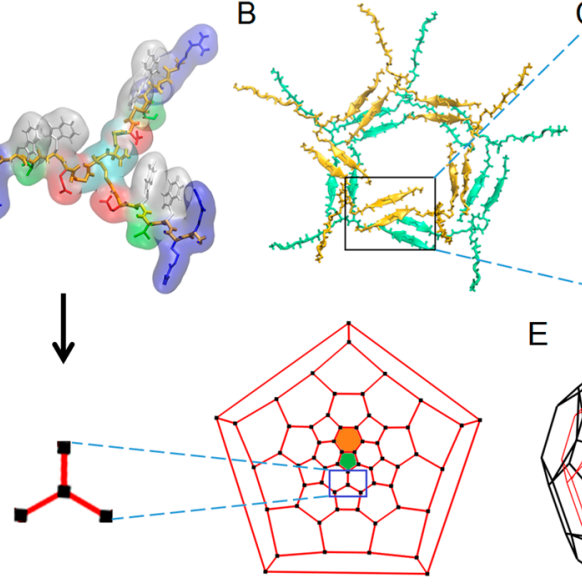

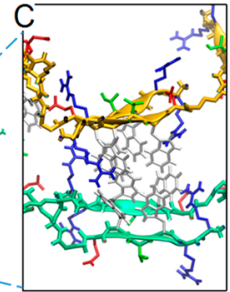

E

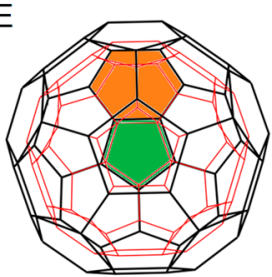

$F$

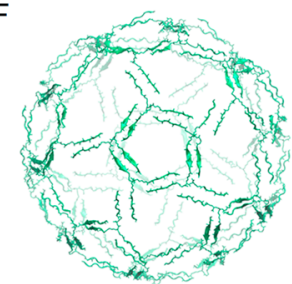

G

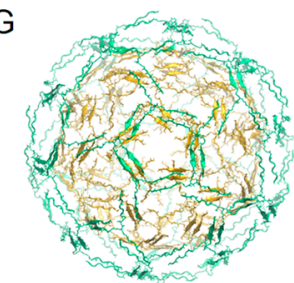

Figure 1. Pseudocapsid design. (A) Molecular model of the triskel RRWTWE conjugate. (B) Snapshot of molecular dynamics simulations showing a pentagonal assembly unit formed by designed triskelions. (C) Two $\beta$-sheet arms (green and yellow) forming a bilayer interface via cross-strand packed tryptophans (gray). (D) Schematic representation of the designed triskelion as a monomer subunit in a truncated icosahedron shown as a 5-fold Schlegel orthographic projection. (E) Five-fold symmetry orthographic projections of two truncated icosahedra (black and red) forming a double-walled assembly. Note: for clarity only one of each of the pentagonal (green) and hexagonal (orange) units is highlighted in (D) and (E). (F) Single-walled triskelion assembly templated on a truncated icosahedron. (G) Double-walled triskelion assembly templated on a truncated icosahedron. Outer and inner layers in (F) and (G) are shown in green and yellow, respectively.

that recognize pathogen surfaces without the need to selfoligomerize. ${ }^{9}$ Yet, in free forms these domains can oligomerize to induce bacteriostatic effects. ${ }^{10}$ This distinction presents a considerable opportunity for antimicrobial engineering. In principle, multiple copies of an effector domain can be arranged to fold into a discrete assembly, ${ }^{11}$ which upon contact with microbial membranes would instantaneously deliver peptide concentrations that significantly exceed those necessary to rupture microbial membranes. An ultimate benefit of such an agent is rapid and irreparable damage to a microbial cell without the need for the transition from unstructured monomers to membrane-active oligomers. As a result, this agent may be equally effective against susceptible, resistant, and persister cells, thus providing a foundation for antibacterial persisters: nanoscale agents whose activity is not subject to bacterial phenotypes and acquired resistance. However, the success of this strategy relies on addressing the following principles.

Since bacteria are $0.2-1 \mu \mathrm{m}$ in width, an assembly of tens of nanometers in diameter would inflict irreparable damage to a bacterial cell. To be discrete at these size ranges, the assembly is best confined to a platonic, symmetrical structure. The nature of the symmetry is of less importance as long as the assembly is locked into a three-dimensional form that is able to bind to microbial membranes. In this regard, viral capsids inspire a straightforward solution. These are self-assembled nanoscale protein cages or cages that do not kill bacteria on contact but provide suitable architectural templates for capsidlike assemblies of effector molecules. The antimicrobial function of the resulting structures permits structural polymorphism that is typical of aberrant and pseudocapsids. ${ }^{12-14}$ Furthermore, it also imposes no a priori constraints on the chirality of the effector domains. Polypeptide chains of reversed chirality, i.e., all-D peptides, are far more stable to proteolysis, fold in a similar manner to that of all-L peptides, and are likely to be nonimmunogenic. ${ }^{15-18}$ Antimicrobial D epimers are as effective as their L counterparts, which is consistent with the fact that host-defense peptides act by binding to the lipid components of bacterial membranes rather than docking to a specific protein. ${ }^{18,19}$ Herein we apply the outlined principles for the design of antimicrobial pseudocapsids or $\Psi$-capsids and demonstrate that such assemblies stand out among artificial and native particulate structures by being biologically persistent agents in vitro and in vivo, delivering nanoprecise antimicrobial effects that do not depend on chirality, with both their $\mathrm{L}$ - and $\mathrm{D}$-forms exhibiting comparable activities.

\section{RESULTS}

Pseudocapsid Design. Our approach adapts a short hostdefense motif from a multifunctional protein lactoferrin, a major component of the innate immune system., ${ }^{9,10}$ The antimicrobial properties of this protein are attributed to its $\mathrm{N}$ terminal domain. The domain has a broad spectrum of targets including porins, DNA, and intracellular metabolites and can stimulate the immune system by neutralizing endotoxin. ${ }^{20-22}$ The host-defense motif of the domain is a hexapeptide RRWQWR, which has strong propensity for antiparallel $\beta$ sheet conformations. ${ }^{23}$

To render this motif self-complementary, the C-terminal arginine of the peptide was replaced with a glutamate. This modification facilitates interstrand Coulombic interactions with the $\mathrm{N}$-terminal arginine of the opposite $\beta$-strand. The core of the motif is also homologous to a characteristic motif of tryptophan zippers, WTW, which folds with cross-strand tryptophan rings packed tightly against one another. ${ }^{24}$ To capitalize on this analogy, the glutamine in the peptide was replaced with a threonyl residue. This modification supports the formation of a tryptophanyl interface to cement a $\beta$-sheet bilayer with two cationic exteriors. In viruses, capsid proteins interface orthogonally with each other to network into pentaand hexagonal assembly units. Each of these units adopts a 3fold rotational symmetry, which ensures their propagation into a closed, spheroid symmetry. ${ }^{25}$ To emulate the 3 -fold symmetry of native cage-like subunits, the resulting monomeric peptide RRWTWE was converted into a triskel conjugate 

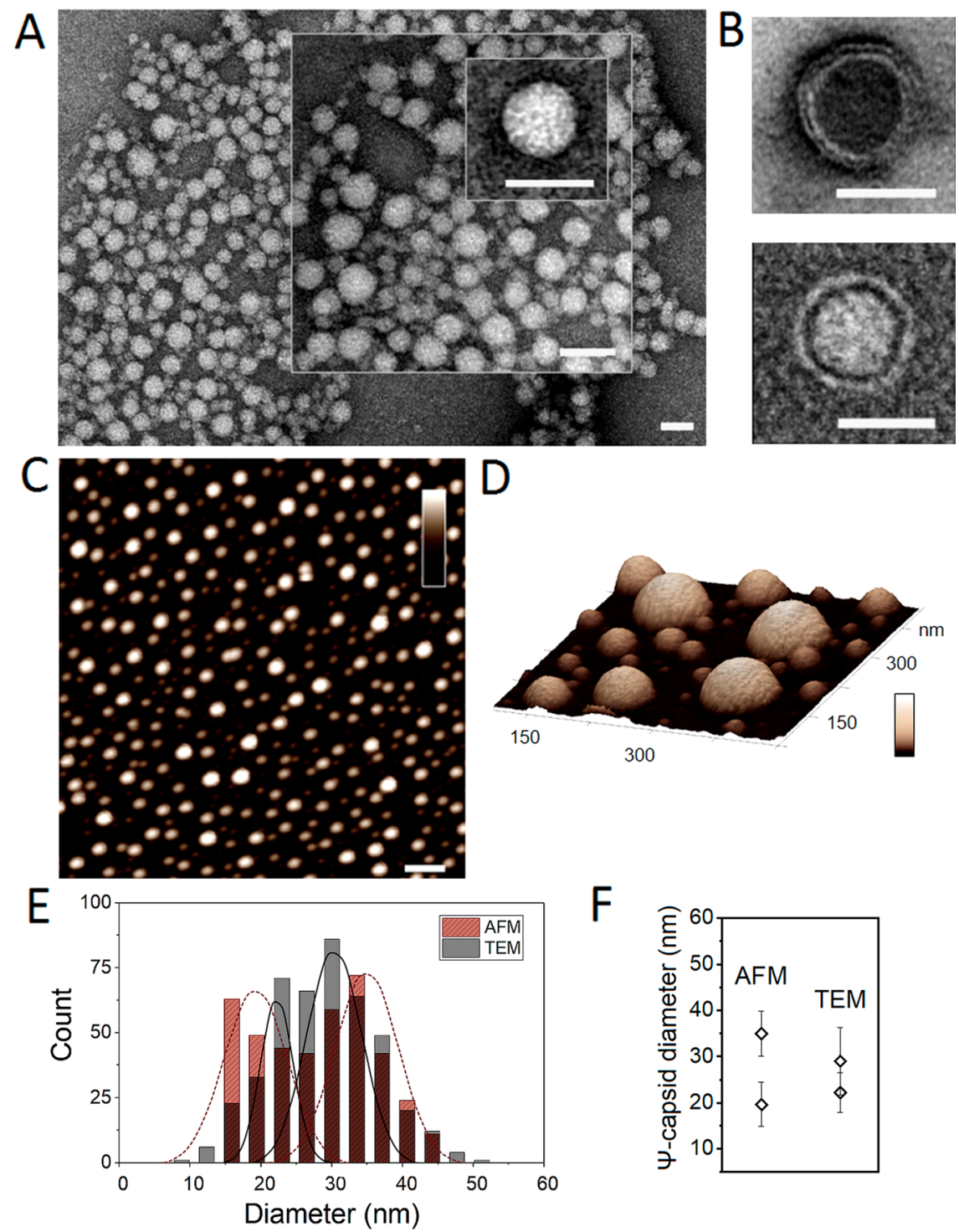

Figure 2. Pseudocapsid assembly. (A) TEM images of assembled D- $\Psi$-capsids. Scale bars are $50 \mathrm{~nm}$. (B) Higher resolution TEM images of individual collapsed negatively (upper) and positively (lower) stained capsids. Scale bars are $50 \mathrm{~nm}$. (C) Topography images of D- $\Psi$-capsids obtained on a mica substrate by AFM in liquid. Color (height) and scale bars are 60 and $200 \mathrm{~nm}$, respectively. (D) 3D representation of D- $\Psi$ capsids. Color (height) bar is $50 \mathrm{~nm}$. (E) Size distributions and dominating sizes of $\mathrm{D}$ - $\Psi$-capsids by AFM and TEM. Error bars denote standard deviations. (F) Average sizes of dominating populations of $\Psi$-capsids. Assembly conditions: $100 \mu \mathrm{M}$ peptide, $\mathrm{pH} 7.4,10 \mathrm{mM}$ MOPS, $20^{\circ} \mathrm{C}$, overnight $(15 \mathrm{~h})$.

(Figures 1A and S1 in Supporting Information), with both Land $\mathrm{D}$-forms of this conjugate chemically synthesized (Figure S2). Each arm of this triskelion pairs in an antiparallel $\beta$-sheet with another arm of another triskelion. Each folded pair of two arms interfaces with another folded pair of two other conjugates (Figure 1B,C). The monomer has a trilateral symmetry, which enables it to assemble into penta- and hexagonal units forming $\beta$-sheet bilayer networks (Figure 1B).

Because $\beta$-strands are stabilized by interstrand interactions, it is physically impossible for the bilayers to have free, "sticky" edges. These have to close on one another. Triskelion structures have an intrinsic nonzero curvature. ${ }^{26,27}$ In propagating $\beta$-sheet networks, the curvature translates into a trans-sheet asymmetry, prompting the spontaneous closure of increasingly curved sheets into a minimum energy spheroid. ${ }^{11,28}$ This mode of assembly is analogous to that of viral particles, which follows an icosahedral symmetry, with a truncated icosahedron being one of the most common architectures. $^{29,30}$ This polygon architecture offers an ideal template for the assembly of triskelions: it has only 3-fold vertices, each of which can host an individual triskelion (Figure $1 \mathrm{D}, \mathrm{E})$. Therefore, if triskelions fold cooperatively within the template, the propagating $\beta$-sheet networks should self-close into an equilibrated and discrete structure. The monolayer configuration of this structure is not stable, as the hydrophobic side chains of the tryptophanyl residues are oriented inward toward its water-filled core (Figure $1 \mathrm{~F}$ ). A $\beta$-sheet bilayer or a double-wall $\beta$-sheet, in which cationic arginyl residues furnish its exterior and interior surfaces, is deemed more stable (Figure $1 \mathrm{C}, \mathrm{G}){ }^{31}$ In support of this conjecture, coarse grain molecular dynamics (MD) simulations ${ }^{32}$ showed that single-wall icosahedra assembled from the triskelion collapsed within the first $600 \mathrm{~ns}$ of simulations following an equilibration phase (Figure S3A). Under the same simulation conditions, double- 
walled structures retained their initial configuration over $1 \mu \mathrm{s}$ of coarse grain simulations, evolving into more compact shapes, for both L- and D-forms, which was also confirmed by 100 ns atomistic simulations ${ }^{33}$ (Figure S3B,C and Movie S1). Further simulations confirmed that the double bilayer maintained $\beta$-sheet networks intact, while allowing individual $\beta$-strand pairs to break and re-engage in the outer layer. This ability of $\beta$-sheets to rearrange without compromising the stability of the assembly renders changes in the networks cooperative and suggests that triskelions can indeed assemble cooperatively in the template, which should manifest in the formation of an equilibrated, discrete, and stable structure (Figure S4).

Pseudocapsid Folding and Assembly. Consistent with the simulations, circular dichroism (CD) spectra for both forms of the triskelion were characteristic of antiparallel $\beta$ sheet and $\beta$-turn conformations (Figure S5A). Fourier transform infrared (FT-IR) spectra revealed bands for the deconvoluted amide regions at $1650-1670 \mathrm{~cm}^{-1}$ for $\beta$-turn structures and at 1630 and $1545 \mathrm{~cm}^{-1}$ for $\beta$-sheets (Figure S5B). These results suggest that inter- and intramolecular hydrogen bonds in $\beta$-sheets and $\beta$-turns, respectively, support the cooperative folding of the triskelions into higher-order structures.

Indeed, transmission electron microscopy (TEM) and atomic force microscopy (AFM), performed in solution, revealed uniformly spherical capsids (Figure 2A-D). Some of these appeared as collapsed or open structures giving a double-walled or double-layered morphology (Figure 2B). Negatively and positively stained capsids gave darker and lighter interiors, respectively, due to stain accumulation. This is characteristic of synthetic virus-like and native virus structures (Figure S6). ${ }^{34,35}$ An enclosing boundary was also apparent, suggesting a space between the two layers (Figure 2B). Since most of the assemblies remained as dense spheroids (Figure 2A), we sought further evidence for the hollow nature of the assembled structures and probed their mechanical properties directly in solution by local nanoindentation with simultaneous topographic imaging (Figure S7). By mapping the effective elastic modulus of the capsids as a function of position on the assembled capsids, ${ }^{36}$ it was found that the capsids were seemingly compliant at their edges. This is expected since the capsids can move sideways in response to the vertically indenting AFM tip. More importantly, however, the capsids were appreciably more compliant to indentation at their centers, compared with surrounding areas. These results, which were consistent across all capsid sizes observed, are indicative of hollow spheroids (Figure S7). The diameters of the spheroids themselves were comparable by both width (TEM) and height (AFM) measurements and were dominated by a narrow size range of $20-40 \mathrm{~nm}$ (Figure 2E,F). An overlapping range of $10-20 \mathrm{~nm}$ was also evident, particularly by height measurements. Since these measurements are performed in solution and without staining, unlike TEM, the results exclude dehydration effects and contributions from stains, which may explain a lesser distinction between particle sizes observed by TEM (Figure 2E,F). The lower size range was half the size of the first one, suggesting that the triskelions may adopt an integer step size in assembly, generating structures that are polymorphic in size but not in shape. The assembled capsids remained in the same two diameter ranges at micro-to-millimolar peptide concentrations; that is, they were not concentration dependent (Figure S8A). The assembly was also complete in the first $2 \mathrm{~h}$ of incubation and did not deviate significantly from the size ranges over $15 \mathrm{~h}$ (Figure S8B). In good agreement with the simulation data (Figures 1 and S3), these results support a cooperatively assembled, stable structure. As expected, the monomeric peptide, which has no capacity to propagate, did not assemble even at high concentrations (Figure S9). This ability of the designed $\Psi$-capsids to accommodate different sizes is akin to that of viral capsids and synthetic virus-like assemblies that can adapt to repack into smaller and larger particles. ${ }^{37-39}$ This is also in marked contrast to mutant viral capsids and polymorphic virus-like particles, whose variations in morphology feature filamentous and aberrant structures with irregular serrations. ${ }^{13,14}$

The designed triskelions are asymmetric dendritic hubs with three peptide arms folding into equivalent $\beta$-strands (Figure $S 1)$. The asymmetry of each hub incorporates reciprocally into the trans-sheet asymmetry of propagating $\beta$-sheet networks. This contribution is additional to the intrinsic curvature of triskelions and helps them adjust to geometric variations in local environments. Turn structures that separate the peptide arms in hubs ensure the three-directional assembly of triskelions without sterically occluding the pairing of peptide arms. These features are complementary to one another and promote $C_{3}$ rotational symmetry, enhancing local symmetry interactions in a cooperative manner that is similar to that of native viruses ${ }^{40}$ and virus-derived systems. ${ }^{34}$ In particular, capsid proteins, which are asymmetric, form quasi 3 -fold contacts to set up identical polygonal subunits that occupy different geometric environments. ${ }^{41}$ This is sufficient for relatively small $(T<4$, where $T$ is a triangulation number $)$ viruses. ${ }^{25}$ Larger capsids are enabled by incorporating large or scaffolding proteins that serve as an inner core on which the capsid assembly can be templated. ${ }^{42}$ Scaffolding proteins for the designed pseudocapsids are not necessary, as the $\beta$-sheet networks arrange into bilayers stabilized by hydrophobic interfaces. These interfaces keep the assembly intact and rectify the impact of broken $\beta$-sheet contacts in the networks through cooperative rearrangements, ${ }^{39}$ i.e., acting as inner templates or cores. This agrees well with the results of MD simulations that showed that such rearrangements take place in the outer part of the bilayer. The hydrophobic face of the inner layer that seeds the interface appears to partially destabilize $\beta$-sheet networks in the outer layer, making them concomitant or "fluid". In contrast, the inner layer itself remains intact in all of its constituent $\beta$-sheets (Figure S4). This property extends to the ability of the triskelions to adapt to size variations in the assembly. Indeed, course grained, optimized assembly simulations of double-wall networks confirmed that the triskelions can readily accommodate the size ranges observed experimentally (Figures 2 and S10).

Taken together the findings indicate that the designed triskelions propagate with the formation of thermodynamically stable $\Psi$-capsids exhibiting a degree of structural plasticity that helps accommodate size variations without compromising on morphological uniformity. Since the triskelions occupy the vertices of pentagonal and hexagonal faces in the truncated icosahedron, rather than tightly pack in the faces, the overall architecture of $\Psi$-capsids remains independent of size allowing for wide size variations. This property renders the assembly adaptable to morphological changes imposed by hierarchically complex and dynamic environments such as microbial membranes. 
A

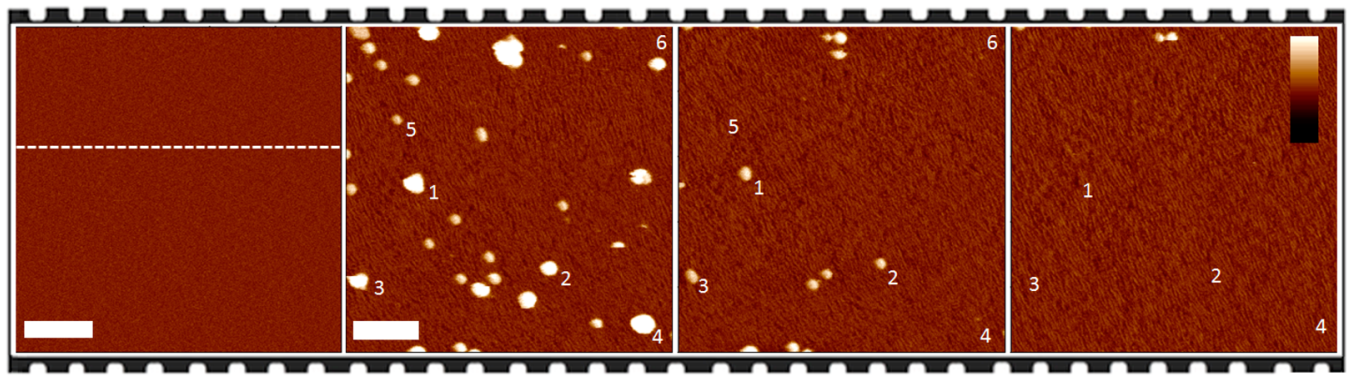

B

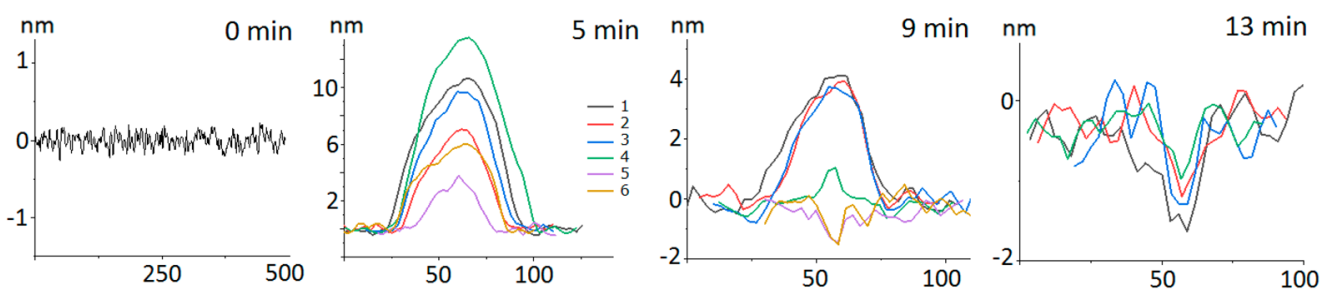

C
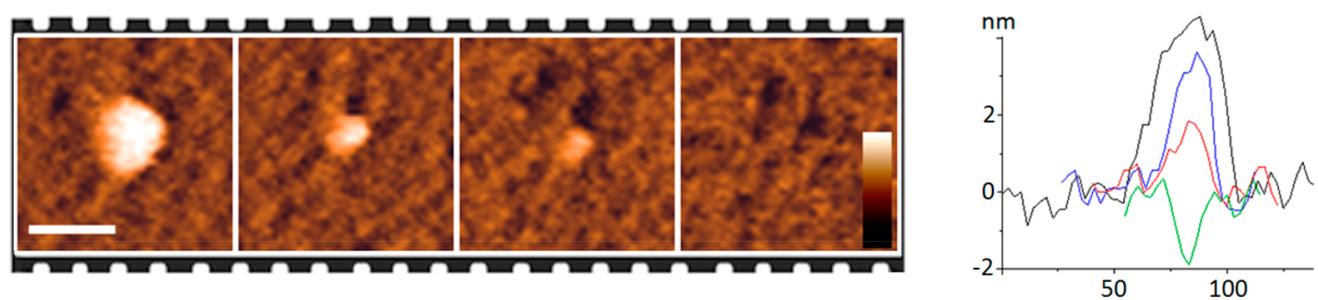

D

$E$
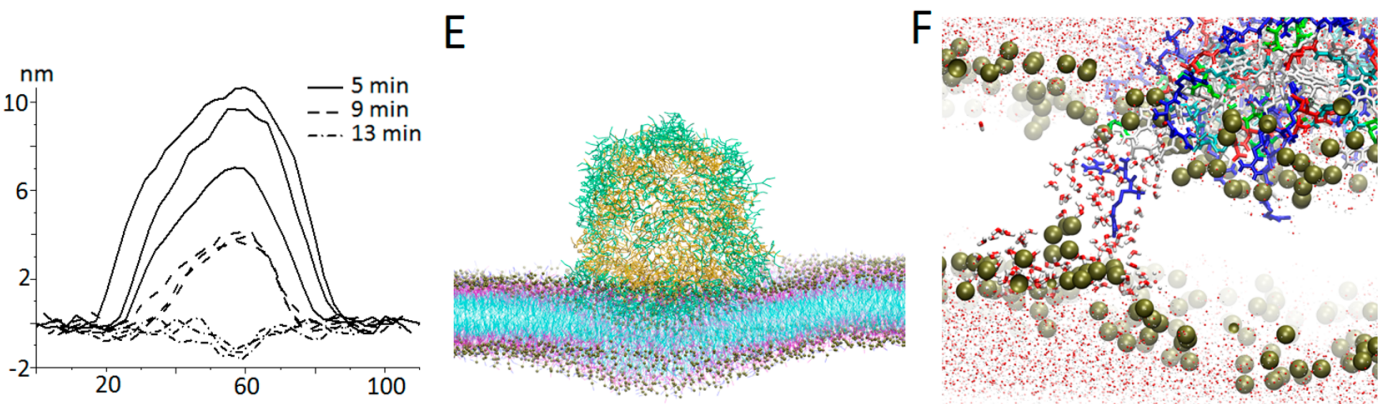

Figure 3. Pseudocapsids porating phospholipid bilayers. (A) In liquid AFM topography of SLBs treated with D/ $\Psi$-capsids. The images are taken at $4 \mathrm{~min}$ intervals. Individual $\Psi$-capsids are numbered (1-6) to highlight conversions into pores. Scale bars are $100 \mathrm{~nm}$ for the first image and $200 \mathrm{~nm}$ for the others. The height (color) bar is $10 \mathrm{~nm}$. (B) Cross-sectional analyses of $\Psi$-capsids numbered as in (A) for each given time point. (C) Topography of a $\Psi$-capsid converting into a pore in $15 \mathrm{~min}$, with the height profiles of the corresponding conversion area. Images are taken at 5 min intervals. Scale and height (color) bars are 50 and $10 \mathrm{~nm}$, respectively. (D) Plot combining height profiles of three $\Psi$-capsids from (A) to show conversions as a function of time. (E) Snapshot of coarse-grain MD simulations of a $\Psi$-capsid binding to a phospholipid bilayer at $2 \mu \mathrm{s}$ and simulated for an additional $8 \mu \mathrm{s}$. Key: outer and inner layers of the $\beta$-sheet bilayer are in green and yellow, respectively; golden beads denote phosphate groups linked to two types of polar groups (blue and magenta); aliphatic lipid tails are in cyan. (F) Snapshot of a rudimentary pore showing a triskelion arm stretching across the bilayer interface after $72 \mathrm{~ns}$ of a $100 \mathrm{~ns}$ atomistic simulation. Key: for clarity, only phosphate groups (golden beads) are shown for the bilayer.

To test their behavior in membranes in sufficient detail, $\Psi$ capsids were introduced into reconstituted phospholipid bilayers that were assembled on mica substrates as described elsewhere. ${ }^{43}$ The resulting supported lipid bilayers (SLBs) provide suitable models for bacterial membranes, are flat (to within $\sim 0.1 \mathrm{~nm}$ ) in their unperturbed state (Figure 3A,B), and allow for the accurate depth measurements of surface changes in solution and in real time by AFM. ${ }^{44}$ As gauged by these measurements, $\Psi$-capsids bound to the SLBs and disintegrated on them forming pore- and channel-like lesions (Figure 3AC).

The conversion of individual assemblies into pores at their precise binding positions was complete within a few minutes of treatment: $\Psi$-capsids gradually sank in the lipid bilayers at the depths of a folded triskelion arm, $\sim 1.8 \mathrm{~nm}(0.3 \mathrm{~nm}$ translation per $\beta$-strand residues) (Figure $3 \mathrm{~A}-\mathrm{D}$ ). Coarse grain simulations of the capsids in the lipid bilayers ${ }^{45}$ run over 10 $\mu$ s revealed that the sinking effect occurred at the expense of pressing and displacing lipids deep into the bilayer interface (Figure 3E, Movie S2). In accord with this, atomistic simulations of a rudimentary pore showed that triskelion arms oriented toward the bilayer interface (Figures 3F and S11 and Movie S3). Such localized responses are consistent with a mechanism where triskelions reassemble in the bilayer and that forming pores do not expand and remain confined within the diameters of $\Psi$-capsids. This is important for three reasons. 

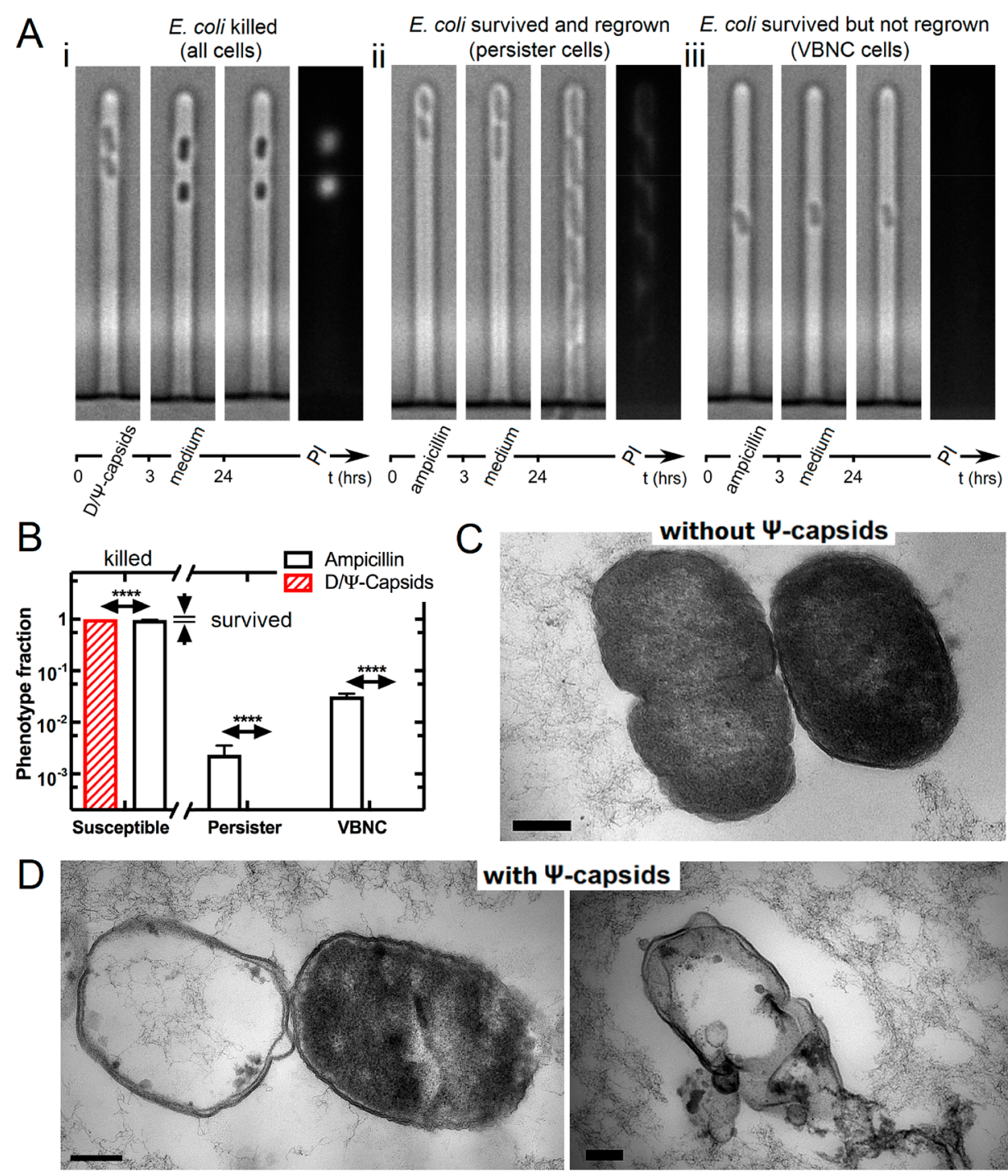

Figure 4. Single-cell antimicrobial kinetics of pseudocapsids. (A) Three panels of representative optical micrographs of E. coli cells (i) killed by $\mathrm{D} / \Psi$-capsids; (ii) survived and regrown after ampicillin treatments (persister cells); (iii) survived but not regrown after ampicillin treatments (VBNC cells). In each panel, image bars show (from left to right) cells after $3 \mathrm{~h}$ treatments with capsids or ampicillin, during subsequent washing with the growth medium over $21 \mathrm{~h}$, and after washing. The last micrographs in the panels are fluorescence images of 24 $\mathrm{h}$ samples stained with propidium iodide (PI), a live-dead stain penetrating dead bacteria with compromised membranes. (B) Cell fractions treated with $\mathrm{D} / \Psi$-capsids and ampicillin. The data and error bars are means and standard error of the means of measurements obtained for 3332 cells hosted in 2331 independent microfluidic channels in four independent biological replicates. The distribution of fractions of susceptible cells to ampicillin was significantly lower than that to $\mathrm{D} / \Psi$-capsids $(p<0.0001)$. The distributions of fractions of persister and VBNC cells to ampicillin were significantly higher than those to $\mathrm{D} / \Psi$-capsids $(p<0.0001)$. (C) Electron micrographs of microtomed $E$. coli cells before treatment with $\mathrm{D} / \Psi$-capsids. The scale bar is $200 \mathrm{~nm}$. (D) Electron micrographs of microtomed E. coli cells after treatment with $\mathrm{D} / \Psi$-capsids. The scale bars are $200 \mathrm{~nm}$.

First of all, the assemblies exhibit a larger structural plasticity than crystalline materials or viruses do, which allows them to rapidly rearrange into peptide-lipid oligomers at the sites of contact with phospholipid membranes. Second, these oligomers maintain the size of the resulting pores close to that of the landed capsids, thereby supporting precise and sitespecific membrane disruption. Third, this behavior suggests that $\Psi$-capsids may support differential responses in cell environments favoring attack on microbial membranes. To gain a better insight into this, the biological properties of $\Psi$ capsids were assessed using a range of in vitro and in vivo assays.

Biological Properties of Pseudocapsids. Irrespective of chirality, $\Psi$-capsids were found to be antimicrobial and nonhemolytic (Table S1). The minimum inhibitory concentrations (MICs) of the capsids were comparable to those of antimicrobial agents including conventional antibiotics (Table S1). The monomeric peptide remained inactive at up to $100 \times$ MICs of the capsids $(>100 \mu \mathrm{M})$ against all bacteria tested. However, the principal advantage of $\Psi$-capsids over antimicrobial compounds lies in their ability to exert rapid and irreparable damage to a bacterial cell, which makes them equally effective against susceptible cells and cells that are tolerant to conventional antibiotics. In liquid AFM experiments showed that the capsids can indeed disrupt membranes within minutes. MIC experiments cannot directly relate to the AFM results, as these are optical density measurements that do not consider changes at the cellular level. Therefore, we sought 

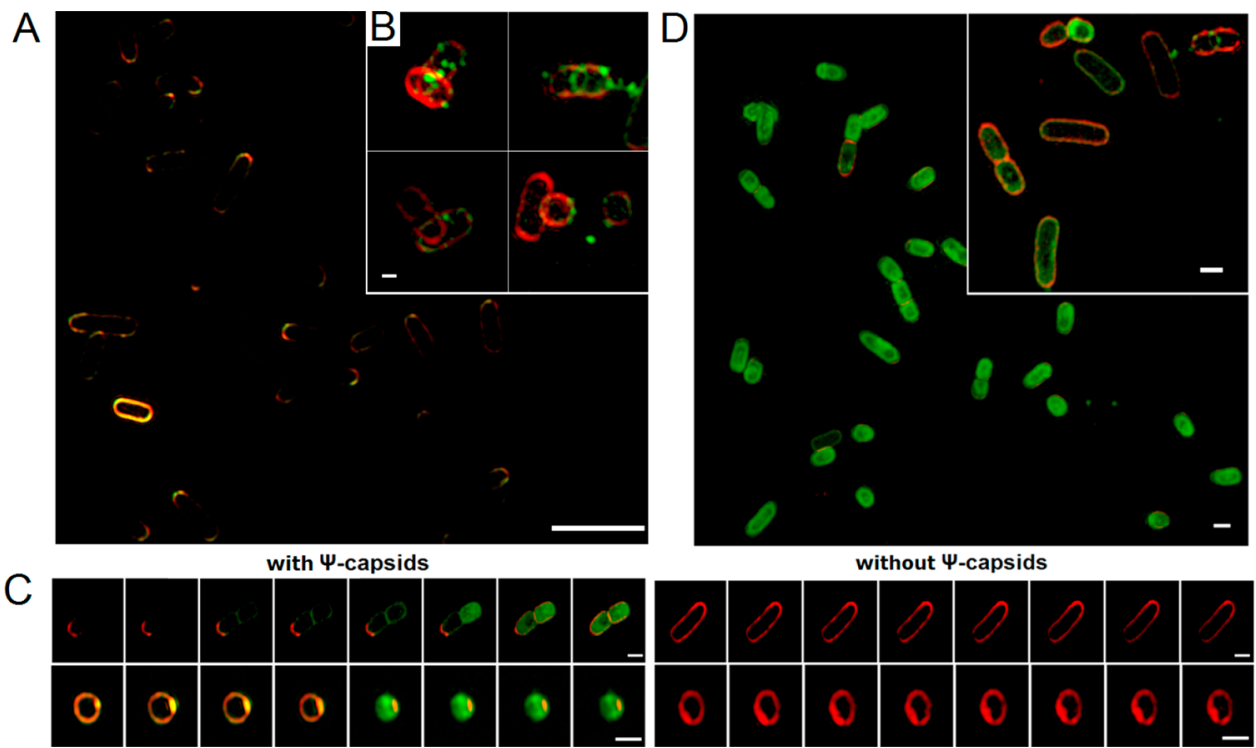

Figure 5. Time-kill kinetics of pseudocapsids in vitro. Structured illumination micrographs of $E$. coli cells (A) immediately after the addition of $\mathrm{L} / \Psi$-capsids and (B) during the treatment highlighting individual capsids in contact with cells. The capsids are labeled with carboxyfluorescein (green). Cell membranes are stained with FM4-64FX (red). Scale bars are $5 \mu \mathrm{m}$ and $500 \mathrm{~nm}$ for (A) and (B), respectively. (C) SIM images recorded at $5 \mathrm{~min}$ intervals for E. coli (upper) and S. aureus (lower) with and without the $\Psi$-capsids. Scale bars are $1 \mu \mathrm{m}$. (D) SIM images of E. coli cells at $45 \mathrm{~min}$ of treatment with carboxyfluorescein-labeled L/ $\Psi$-capsids.

complementary evidence from three series of experiments using planktonic and sessile bacterial culture of two of the most common pathogens, E. coli and S. aureus. In the first series, the antimicrobial activity of $\Psi$-capsids was assessed as a measure of total cell counts following capsid treatments. ${ }^{11}$ Negligible cell counts were observed for cultures treated with the capsids in comparison to the samples of untreated cells in which appreciable bacterial growth was observed (Figure S12). These findings provide end-point results of treated cell populations obtained over the same time scale as MIC measurements. To elucidate the antimicrobial kinetics of $\Psi$ capsids within the first hours and with a single-cell resolution, the second series of experiments was conducted. In these experiments thousands of individual E. coli cells were screened using a high-throughput microfluidic device comprising thousands of growth channels. ${ }^{46}$ Each channel serves as a trap for an individual cell where the cell can grow through one of its distal poles, whereas the diameter of the channel matches that of the cell, thereby arresting its movement. ${ }^{47}$ The replicative age of this trapped, mother, cell increases by one generation at each cell division, allowing to follow phenotypic cell inheritance for an infinite number of generations. Such a "mother machine" then enables the single-cell monitoring of antimicrobial kinetics in situ and is able to reflect the responses of different cell phenotypes to antimicrobial agents. ${ }^{48}$ With this in mind, $\Psi$-capsids were introduced into $E$. coli cells trapped in the channels of the device (Figure 4A).

After $3 \mathrm{~h}$ of treatment under a constant flow the microfluidic environment was replaced by flowing the culture medium over $21 \mathrm{~h}$ to restore normal conditions for bacterial growth. Subsequent analyses revealed that $\Psi$-capsids killed all encountered cells (Figure 4). By contrast, persister cells and viable but not-culturable (VBNC) cells were found after ampicillin treatments (Figure 4A,B). These tolerant phenotypes represent common subpopulations in clonal bacterial cultures that persist antibiotic treatments even at high doses. ${ }^{49}$ Persister cells resume growth after the drug is removed from their environment, whereas the regrowth of VBNC cells often requires specific conditions. ${ }^{50,51}$ Both phenotypes contribute to infection relapses, prompting repetitive treatments, and can be linked to dormancy. ${ }^{52}$ With $\Psi$-capsids effectively reducing these phenotypes to susceptible cells, changes in cell morphology may shed light on the mechanism of action at the single-cell level. Indeed, the capsid-treated cells appeared shrunk and somewhat denser when compared to unaffected cells, suggesting that the capsids accumulated in the membranes. This is consistent with the AFM results (Figure $3)$, although the cells in the mother machine did not disintegrate and seemed intact (Figure 4B). Therefore, cells treated with capsids were microtomed and imaged by TEM (Figure 4C,D). Complete membrane destruction was evident (Figure 4D). Intriguingly, however, many cells appeared as empty and half-empty, having displaced and bulging membranes that tended to open up at distal poles (Figure 4D). This effect is not normally observed for bacteria damaged by host-defense peptides or membrane-active antibiotics, which porate bacterial membranes indiscriminately, causing cells to shrink and leak ${ }^{43}$ or, as polymyxins, aggregate with lipopolysaccharides into membrane-destabilizing blebs across the whole bacterial surface. ${ }^{53}$ The emphasis on distal poles is reminiscent of bacteriophages that preferentially target the poles of bacterial cells. ${ }^{54}$ Although, like polymyxins, $\Psi$-capsids favor anionic lipids, morphologically they are more of phage mimetics that may be attracted to outward membrane curvature or cell poles serving as DNA mobilization sites before cell division. ${ }^{54,55}$ The third series of experiments provided further insight into this. The attack of $\Psi$-capsids on E. coli cells was monitored by structured illumination microscopy (SIM), which was custom designed to image biomolecular and cellular processes in situ. ${ }^{56-58}$

The capsids rapidly adhered to the cell surfaces, with adsorption at the distal poles being also apparent (Figure 5A). Within a doubling time (20 $\mathrm{min})$, the capsids proved to come into direct contact with the cells accumulating in their 


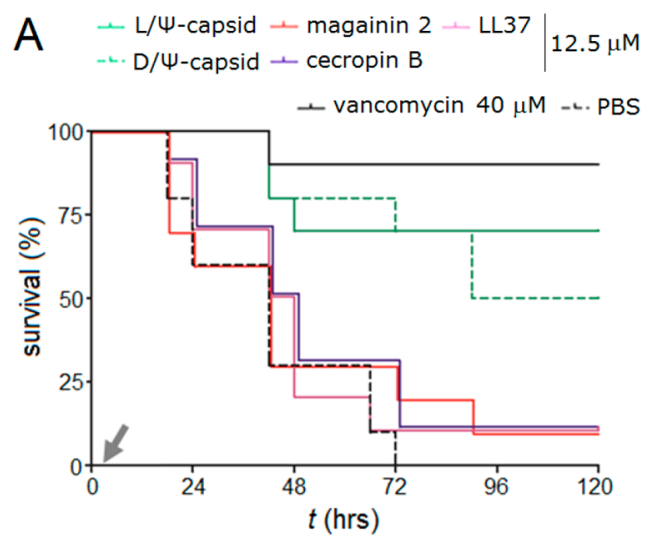

$$
\begin{aligned}
& \leftarrow \mathrm{L} / \Psi \text {-capsid } 12.5 \mu \mathrm{M} \\
& + \text { vancomycin } 40 \mu \mathrm{M} \text {-ᄂ. PBS }
\end{aligned}
$$

C
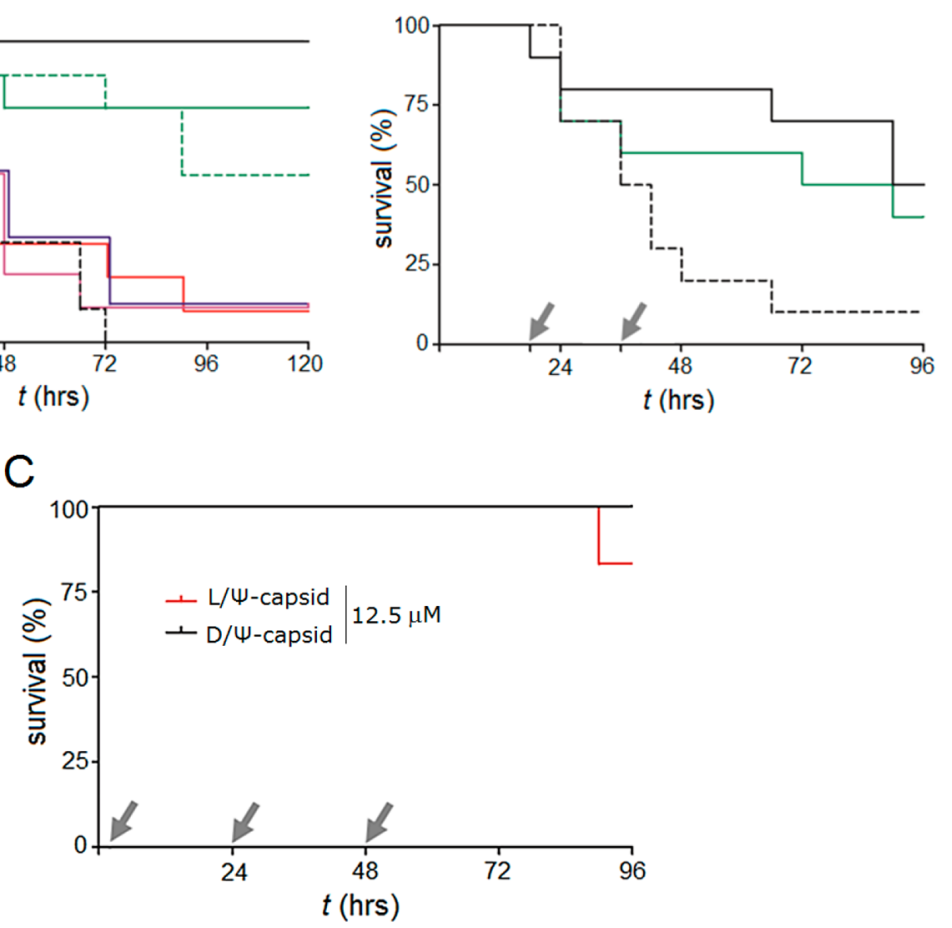

Figure 6. Time-kill kinetics of pseudocapsids in vivo. (A) Survival of G. mellonella larvae infected with vancomycin-susceptible MRSA NCTC12493 strain when treated with $\Psi$-capsids and host-defense peptides. Vancomycin and phosphate-buffered saline (PBS) were used as positive and negative controls, respectively. Inoculations were done straight after the initiation of infection (first $2 \mathrm{~h}$ ) without subsequent treatments. (B) Survival of MRSA-infected G. mellonella larvae treated with vancomycin, L/ $\Psi$-capsids, and PBS, administered at 18 and $36 \mathrm{~h}$ after the initiation of infection. Survival rates for $\Psi$-capsids were significantly higher when compared to PBS control (Mantel-Cox test, $p<$ 0.001). Gray arrows indicate inoculation time points. (C) Survival of $G$. mellonella larvae treated with $\Psi$-capsids. Inoculations were done straight after the initiation of infection (first $2 \mathrm{~h}$ ) with two subsequent treatments at 24 and $48 \mathrm{~h}$.

membranes and cytoplasm (Figure 5B,C). The affected cells then underwent sharp rupture accompanied by a burst of fluorescence intensity (Figure 5C and Movie S4). This effect was more profound in cocci cells ( $S$. aureus). Although the distal poles of these cells are less defined, the transition from the initial contact with $\Psi$-capsids to the disintegration of their only membrane was somewhat sharper when compared to that for E. coli (Figure 5C and Movie S5). The killing for both bacteria was complete within $45 \mathrm{~min}$ (Figure 5D and Movies S4 and S5), while the time of cell disruption closely matched that needed for the conversion of the capsids into membranedisrupting pores as gauged by AFM (Figure 3). Collectively, these findings suggest that $\Psi$-capsids need not disintegrate in the membranes, which they may effectively traverse reaching the protoplasm. Such a mode of action infers that the capsids may be able to circulate intact in cellular environments that are challenged by sustained and active bacterial growth.

To verify this in a biologically relevant model, $\Psi$-capsids were administered into G. mellonella larvae infected with a methicillin-resistant $S$. aureus (MRSA) strain susceptible to vancomycin. ${ }^{59,60}$ Over the first $48 \mathrm{~h}$ the treatments were as effective as those by high doses of vancomycin (Figure 6A). The survival rate of up to $80 \%$ proved to be steady for another $24 \mathrm{~h}$ for larvae treated with $\mathrm{D} / \Psi$-capsids, whereas a $10 \%$ drop was observed for larvae treated with the L-form (Figure 6A). The resulting rate of $70 \%$ did not change over the total of 120 $\mathrm{h}$ of treatment for $\mathrm{L} / \Psi$-capsids. In comparison, for the $\mathrm{D}$-form it dropped to $50 \%$ on day 4 , suggesting a depletion of the capsids in the larvae. The exact reason for this is unclear, although the decrease is likely to link to the fact that $\mathrm{D} / \Psi$ capsids were more active during the first $72 \mathrm{~h}$, possibly at the expense of more capsids being engaged with bacteria (Figure $6 \mathrm{~A})$.

The observed survival rates of the larvae proved to be superior over those reported for membrane-active antibiotics and bacteriocins, indicating that the capsids may be equally effective in killing bacterial cells from the outside and inside. $^{60,61}$ These experiments also demonstrate the importance of preassembling effector monomers into the pseudocapsids. In particular, they provide evidence for the pseudocapsid assembly enabling prolonged antimicrobial effects. This is further emphasized by the failure of standalone host-defense peptides to exert any effects under the same conditions. For instance, the administration of strongly bactericidal human (LL37), insect (cecropin B), and animal (magainin 2) antimicrobial peptides into the infected larvae did not improve survival rates relative to those of mock injections with PBS (Figure 6A). Partly, this failure can be attributed to the enzymatic instability of the nonassembling peptides in vivo. However, both $\mathrm{L}^{-}$and $\mathrm{D}$-forms of the pseudocapsids were similarly effective, which points out that it is the capsid assembly itself that determines the sustained antimicrobial activity. Furthermore, the capsids maintained high rates of bacterial clearance even when administered at 
significantly delayed injection times: the larvae treated with capsids at 18 and $36 \mathrm{~h}$ exhibited a $50 \%$ survival up to day 4 postinfection (Figure $6 \mathrm{~B}$ ), which is twice the time achieved by bacteriophage therapies. $^{62}$ Finally, multiple injections of the capsids into uninfected larvae did not lead to appreciable cytotoxic effects (Figure 6C).

\section{CONCLUSIONS}

We have demonstrated that discrete pseudocapsids assembled from effector molecules deliver rapid and irreparable damage to bacterial cells. The damage results from a direct impact that such assemblies have on cells and ensues via multiple avenues starting with the rapid conversion of the pseudocapsids into membrane-disrupting pores. Pore formation is spatially confined to the binding position of a pseudocapsid, which ensures the rapid and highly localized influx of high antimicrobial doses at the site of contact. Such an impact is different from that of organic or inorganic nanoparticles that rupture membranes indiscriminately by a purely physical means, are unable to disintegrate, and are prone to agglomeration. In contrast, the protein pseudocapsids are cooperative ensembles of monomeric units that reassemble in membranes and integrate into the protoplasm. Thus, these ensembles are equilibrated, symmetry-driven nanoscale systems, which is a prerequisite if they are to remain autonomous within the set size range. ${ }^{25,63,64}$ The polygonal architecture of viral capsids proved to be a suitable framework for templating the assembly of monomeric units, which can be of virtually any chirality and topology. The framework is compatible with the double-layered arrangement of $\beta$-sheet networks that are stabilized by hydrophobic interfaces running tangentially to the capsid surface. Apart from the cases of scaffolding proteins, viral capsids employ single-layered $\beta$-pleated networks in this orientation (e.g., rhino- or poliovirus), which are typically built of closed $\beta$-barrel structures. ${ }^{65}$ To this end, in synthetic peptide and protein cages such networks have been viewed as single-layered structures. ${ }^{11,39}$

An efficient strategy for the design is to repurpose hostdefense effector molecules into structurally and functionally tunable motifs that are furnished with the ability to rapidly selfassemble. Individually, both monomeric units and the motifs may resemble membrane-active antibiotics, but their efficacy is no longer subject to the lag phase of reaching a critical threshold concentration on bacterial surfaces. Once assembled into a discrete pseudocapsid, the constituent monomers acquire a dual capacity of preconcentrated and stimuliresponsive antimicrobial doses. This preassembly of the monomers defines the ability of the capsids to differentiate between bacteria and erythrocytes. With the surfaces of red blood cells being weakly anionic, strong antimicrobial activities often carry an additional cost of hemolytic effects, which is common for toxin or venomous peptides such as bacteriocins or melittins (Table S1). The designed pseudocapsids are different in that they assemble from peptide monomers that individually are not antimicrobial but have an inherent ability to bind to microbial membranes. Therefore, the capsids themselves are antimicrobial agents that exert their activity through highly localized disruption of microbial membranes, accompanied by the conversion of the capsids into pores. Since the capsids did not lyse erythrocytes and were not cytotoxic in vivo, the mechanism supports the differential activity of the design. This biological responsiveness builds upon the structural plasticity of the capsids, ${ }^{11,66}$ and, subsequently, requirements for nanoscale order are looser than those for viral subunits that tune their assembly to the size of encapsidated genomes. Like other paracrystals, which often exhibit periodic nanoscale patterns (e.g., striations or rings), ${ }^{67,68}$ the designed pseudocapsids display fine surface structure (Figure $2 \mathrm{~A}-\mathrm{D}$ ). Although this did not feature readily recognizable patterns, the assemblies appeared to adopt a size integer and were monomorphic in shape, lacking competing morphologies such as filaments. ${ }^{69}$ Combined, these properties represent a highly effective antimicrobial system that, unlike antibiotics, is not frustrated by antibiotic-tolerant phenotypes, such as persister or VBNC cells, or by "superbugs" such as MRSA, killing all. This outcome is notable in that the design may provide a useful tool to aid in a better understanding of how different bacteria phenotypes can be distinguished and selectively targeted. ${ }^{70}$

A question remains as to how universal pseudocapsids are in overcoming different resistance mechanisms including cell surface fortifications, efflux pump blockages, or peptide antagonists that block access to cell membranes. ${ }^{71-74}$ As it has been long postulated ${ }^{75}$ and re-emphasized recently, ${ }^{76}$ hostdefense polypeptides are evolutionarily conserved molecules, against which a widespread resistance cannot be developed easily. Resistance mechanisms against them exist but are not deemed systemic and are readily counteracted by relatively marginal alternations in peptide structure. ${ }^{76,77}$ In this light, the pseudocapsids introduced here may constitute a step change in the applied chemistry of host-defense effector molecules shifting the host-pathogen arms race in favor of more sustainable and adaptable antimicrobial treatments, serving an ultimate pursuit of reducing the spread of antimicrobial resistance.

\section{METHODS}

Peptide Synthesis and Purification. L- and D-Triskelions-(RRWTWE)- $\beta$ A-K(RRWTWE)-K(RRWTWE)-am-were assembled on a Liberty microwave peptide synthesizer (CEM) using standard Fmoc/t $\mathrm{Bu}$ solid-phase protocols with HBTU/DIPEA as coupling reagents on a Rink amide MBHA resin. Fmoc-K(Mtt)-OH was used to enable orthogonal conjugation via a trifunctional dendritic hub, $\beta$ AKK-am. Carboxyfluorescein-labeled triskelions were made on resin by coupling carboxyfluorescein to the $\mathrm{N}$-terminus of $\beta$ A-RRWTWE- $\beta$ AKK, with fully protected side chains, on the resin. The remaining two arms were then assembled on resin following Mtt removal. Magainin 2 and cecropin B were synthesized as peptide amides on a Rink amide MBHA resin, and LL37 was assembled as a peptide acid on an Fmoc-S $\left({ }^{\mathrm{t}} \mathrm{Bu}\right)$-Wang resin. After postsynthesis cleavage and deprotection (95\% TFA, 2.5\% TIS, $2.5 \%$ water) all peptides were purified by semipreparative reversed-phase highperformance liquid chromatography (RP-HPLC). Peptide identities were confirmed by analytical RP-HPLC and MALDI-ToF.

MS $[\mathrm{M}+\mathrm{H}]^{+}$: cecropin $\mathrm{B}, \mathrm{m} / z 3834.6$ (calc), 3836.0 (found); LL37, $m / z 4493.2$ (calc), 4495.8 (found); magainin $2, m / z 2465.9$ (calc), 2467.0 (found); L-triskelion, $\mathrm{m} / z 3090.5$ (calc), 3092.3 (found); D-triskelion, $\mathrm{m} / z$ 3090.5 (calc), 3092.8 (found); monomer, $\mathrm{m} / z 932$ (calc), 932.6 (found); carboxyfluorescein-L-triskelion, $\mathrm{m} / z$ 3518.9 (calc), 3519.7 (found).

Analytical and semipreparative RP-HPLC was performed on a JASCO HPLC system (PU-980; Tokyo, Japan), using Vydac C18 analytical and semipreparative (both $5 \mu \mathrm{m}$ ) columns. Both analytical and semipreparative runs used a $10-70 \% \mathrm{~B}$ gradient over $30 \mathrm{~min}$ at 1 $\mathrm{mL} / \mathrm{min}$ and $4.5 \mathrm{~mL} / \mathrm{min}$, respectively, with detection at 280 and 214 $\mathrm{nm}$ (buffer $\mathrm{A}, 5 \%$, and buffer $\mathrm{B}, 95 \%$ aqueous $\mathrm{CH}_{3} \mathrm{CN}, 0.1 \%$ TFA).

$\Psi$-Capsid Assembly. Triskelions were assembled overnight at the concentrations stated in the text $(100-400 \mu \mathrm{M})$ in filtered $(0.22 \mu \mathrm{m})$, 
$10 \mathrm{mM}$ MOPS, phosphate, or PBS buffers, $\mathrm{pH} 7.4$, at room temperature.

Circular Dichroism Spectroscopy. CD spectra were recorded on a JASCO J-810 spectropolarimeter fitted with a Peltier temperature controller. The measurements were taken in ellipticities in mdeg and converted to molar ellipticities $\left([\theta], \operatorname{deg~cm}{ }^{2} \mathrm{dmol}^{-1}\right.$ $\mathrm{res}^{-1}$ ) by normalizing for the concentration of peptide bonds. The data were collected with a $1 \mathrm{~nm}$ step, $1 \mathrm{~s}$ collection time per step, and are presented as the average of 4 scans.

Fourier Transform Infrared Spectroscopy. FT-IR spectra were recorded using a Tensor-27 series FTIR spectrometer equipped with a BioATR II unit (Bruker Optics), as the sampling platform, and a photovoltaic mercury cadmium telluride (MCT) detector and a Bruker Optics workstation equipped with OPUS software. Lowvolume $(20 \mu \mathrm{L})$ capsid samples $(100 \mu \mathrm{M})$ were placed in a circular sampling area of radius $2 \mathrm{~mm}$ with a path length of $6 \mu \mathrm{m}$. FT-IR spectra was recorded with resolution $4 \mathrm{~cm}^{-1}$, scanner velocity $20 \mathrm{kHz}$, 256 scans, phase resolution 32, and zero filling factor 4. Spectra deconvolutions were performed by Gaussian peak fitting using the proprietary software.

Molecular Dynamics Simulations. MD simulations were performed using the GROMACS 2016 software with the GROMOS96 53A6 force field (atomistic) and the MARTINI force field (coarse grain). ${ }^{32,33}$ An SPC water model was used for atomistic simulations and standard MARTINI water for coarse grain simulations. In all simulations chloride and sodium ions were added up to a $150 \mathrm{mM}$ concentration. Additional ions were placed if required for charge neutralization. The initial $\Psi$-capsid configuration was constructed geometrically using the editconf tool from GROMACS. The DLPC/DLPG (3:1) membrane was constructed with the PACKMOL software with dimensions of $12 \times 12 \mathrm{~nm}$ (atomistic) or $30 \times 30 \mathrm{~nm}$ (coarse grain). ${ }^{43}$ Periodic boundary conditions were imposed, setting the minimal distances between the protein and the box boundaries to $3 \mathrm{~nm}$. All simulations are run in the NPT ensemble maintaining the temperature at $303 \mathrm{~K}$ with the velocity rescale thermostat, and the pressure at 1 bar using the Parrinello-Rahman barostat, with either an isotropic or semiisotropic coupling; simulations without and with membranes, respectively. For atomistic simulations of the $\Psi$-capsid in solution, multiple restrained equilibration runs $(65 \mathrm{~ns}$ overall) precede $100 \mathrm{~ns}$ productions, which were run in three replicates. Similarly, for coarse grain simulations a $10 \mathrm{~ns}$ equilibration precedes $1 \mu$ s productions, which were run in three replicates. For simulations including membranes, the lipid patches were equilibrated for $500 \mathrm{~ns}(1 \mu \mathrm{s}$ for coarse grain) before placing the peptide close in contact with the lipid surface (atomistic) or at the minimal distance of $1 \mathrm{~nm}$ (coarse grain). Production was then carried out for $500 \mathrm{~ns}$, and $10 \mu$ s for coarse grain. Atomistic simulations with membranes were run with an electric field of $130 \mathrm{mV} / \mathrm{nm}$ in the direction perpendicular to the membrane, with the higher potential region on the side of the bilayer where the peptide rests. Coarse grain MD modeling of double-walled $\Psi$-capsids was performed using the PACKMOL software: the capsids were constructed as two spherical cages, their radii defined by the number of triskelions packed into a single bilayer with a hydrophobic interface. $^{43}$ The same, optimal packing of triskelions was used for all the sizes.

Transmission Electron Microscopy. Micrographs of the $\Psi$ capsids were recorded using a JEOL 1010 transmission electron microscope equipped with an Orius SC1000 (Gatan Inc.) CCD camera, operated at $80 \mathrm{keV}$. Droplets of capsid solution were placed on glow-discharged $\mathrm{Cu}$ finder grids coated with carbon film (mesh 200) or holey carbon film with graphene oxide (mesh 300), stained with uranyl acetate (aqueous $2 \%, \mathrm{w} / \mathrm{v}$ ) for a few seconds, and buffer excess was removed by blotting paper. Micrographs of $E$. coli were recorded using a FEI Tecnai T12 transmission electron microscope equipped with a Morada G2 (Olympus Inc.) camera, operated at 80 $\mathrm{keV}$. Samples were fixed with glutaraldehyde (aqueous 5\%, w/v), treated with a postfixation agent osmium tetroxide $(1 \%, \mathrm{w} / \mathrm{v}, 100 \mathrm{mM}$ PIPES, $\mathrm{pH}$ 7.2), and stained with uranyl acetate (aqueous $2 \%, \mathrm{w} / \mathrm{v}$ ). The resulting samples were embedded in a Spurr resin and were left to solidify at $60{ }^{\circ} \mathrm{C}$, over $24 \mathrm{~h}$. The resin was then microtomed to ultrathin sections, which were placed on Formvar carbon coated grids (mesh 200), poststained using lead citrate (aqueous 5\%, w/v), and imaged.

Electron micrographs of MS2 bacteriophages were recorded using a JEOL JEM1400-Plus transmission electron microscope equipped with a OneView 4K (Gatan) camera, operated at $120 \mathrm{keV}$. Droplets of phages in SM buffer ( $\mathrm{pH} 7.5)$ were deposited on Formvar carbon coated copper grids (mesh 200), stained with uranyl acetate (aqueous $1 \%, \mathrm{w} / \mathrm{v}$ ) for $2 \mathrm{~min}$, and blotted with a filter paper. The phages were purchased from ATCC (Escherichia coli bacteriophage MS2, ATCC 15597-B1) and were cultured according to the proprietary protocols.

In-Liquid AFM and Peak Force QNM Imaging. Pseudocapsids were assembled overnight at $100 \mu \mathrm{M}$ in $10 \mathrm{mM}$ MOPs, $\mathrm{pH}$ 7.4, room temperature. A $50 \mu \mathrm{L}$ sample of assembled solution was added to freshly cleaved mica, prehydrated with $50 \mu \mathrm{L}$ of imaging buffer $(120$ $\mathrm{mM} \mathrm{NaCl}, 20 \mathrm{mM}$ MOPs, $\mathrm{pH}$ 7.4). Imaging was performed using PeakForce Tapping mode on a Multimode 8 AFM system (Bruker AXS, USA) using MSNL-E cantilevers (Bruker AFM probes, USA) and a $100 \mu \mathrm{L}$ fluid cell (Bruker AXS, USA). Images were taken at a PeakForce frequency of $2 \mathrm{kHz}$, PeakForce amplitude of $20 \mathrm{~nm}$, and PeakForce set-point of $10-30 \mathrm{mV}(<100 \mathrm{pN})$. Both topography and DMT modulus channels were recorded. Images were processed using Gwyddion (http://gwyddion.net) for first-order line-by-line background subtraction (flattening), first-order plane fitting, and cross correlation averaging.

Preparation of Unilamellar Phospholipid Vesicles for AFM Imaging. 1,2-Dilauroyl-sn-glycero-3-phosphocholine (DLPC) with 1,2-dilauroyl-sn-glycero-3-phospho-( $1^{\prime}$-rac-glycerol) (DLPG) lipids used for vesicle construction were from Avanti Polar Lipids (Alabaster, AL, USA). DLPC was used as mammalian model membranes, and DLPC/DLPG (3:1, molar ratios) was used as bacterial model membranes. The lipids were weighted up, dissolved in chloroform-methanol $(2: 1, \mathrm{vol} / \mathrm{vol})$, and dried under a nitrogen stream and then under vacuum to form a thin film. The film was hydrated in $10 \mathrm{mM}$ phosphate buffer ( $\mathrm{pH} 7.2)$ with shaking ( $1 \mathrm{~h}, 220$ $\mathrm{rpm}$ ) and bath sonicated for $30 \mathrm{~min}$. The obtained suspension was extruded using a hand-held extruder (Avanti Polar lipids) (29 times, polycarbonate filter, $0.05 \mu \mathrm{m}$ ) to give a clear solution of small unilamellar vesicles, the sizes of which $(50 \mathrm{~nm})$ were confirmed by photon correlation spectroscopy.

In-Liquid AFM on Supported Lipid Bilayers. Supported lipid bilayers were formed using a vesicle fusion method as described elsewhere. ${ }^{42}$ Freshly prepared vesicles $(1.5 \mu \mathrm{L}, 3 \mathrm{mg} / \mathrm{mL})$ were added to cleaved mica prehydrated with buffer $(70 \mu \mathrm{L}, 120 \mathrm{mM} \mathrm{NaCl}, 20$ $\mathrm{mM}$ MOPS, $20 \mathrm{mM} \mathrm{MgCl}$ ). Following adsorption and incubation for $45 \mathrm{~min}$, the samples were washed to remove unfused vesicles, and resulting SLBs were checked to confirm they were defect free. Peptides were then introduced into a $100 \mu \mathrm{L}$ fluid cell (Bruker AXS, USA), where they were diluted to the final concentrations of $0.1-0.8$ $\mu \mathrm{M}$. All imaging was performed using PeakForce Tapping mode on a Multimode 8 AFM system (Bruker AXS, USA) using MSNL-E cantilevers (Bruker AFM probes, USA). Images were taken at a PeakForce frequency of $2 \mathrm{kHz}$, PeakForce amplitude of $10 \mathrm{~nm}$, and PeakForce set-point of $10-30 \mathrm{mV}(<100 \mathrm{pN})$. Images were processed using Nanoscope analysis software (Bruker AXS, USA) or Gwyddion (http://gwyddion.net) for first-order line-by-line background subtraction (flattening) and first-order plane fitting.

Photon Correlation Spectroscopy. Prepared phospholipid vesicles for AFM imaging were resuspended to a final concentration of $1 \mathrm{mg} / \mathrm{mL}$ and were analyzed on a Zetasizer Nano (ZEN3600; Malvern Instruments). Dynamic light scattering batch measurements were carried out in a low-volume disposable cuvette at $25{ }^{\circ} \mathrm{C}$. Hydrodynamic radii were obtained through the fitting of autocorrelation data using the manufacturer's Dispersion Technology Software (version 5.10).

Minimum Inhibitory Concentrations Assay. Minimum inhibitory concentrations were determined by broth microdilution on $P$. aeruginosa, E. coli, S. aureus, M. luteus, B. subtilis, S. typhimurium, and K. pneumoniae according to the Clinical and Laboratory Standards 
Institute. Typically, $100 \mu \mathrm{L}$ of $(0.5-1) \times 10^{6} \mathrm{CFU}$ per $\mathrm{mL}$ of each bacterium in Mueller Hinton media broth (Oxoid) was incubated in 96-well microtiter plates with $100 \mu \mathrm{L}$ of serial 2-fold dilutions of the capsids (from 100 to $0 \mu \mathrm{M}$ ) at $37{ }^{\circ} \mathrm{C}$ on a $3 \mathrm{D}$ orbital shaker. The absorbance was measured after capsid addition at $600 \mathrm{~nm}$ using a SpectraMax i3x Multi-Mode microplate reader (Molecular Devices). MICs were defined as the lowest peptide concentration that inhibited visible bacterial growth after $24 \mathrm{~h}$ at $37^{\circ} \mathrm{C}$. All tests were done at least in triplicate, and results are summarized in Table S1. The values that are given without standard deviations are those for which no variations were found within triplicates.

Hemolysis Assay. Hemolysis was determined using human erythrocytes sourced commercially from Cambridge Bioscience Ltd. and used within 2 days; $10 \%$ (v/v) suspensions of human erythrocytes were incubated with the capsids. The cells were rinsed four times in $10 \mathrm{mM}$ phosphate buffer saline (PBS, Gibco), $\mathrm{pH}$ 7.2, by repeated centrifugation and resuspension $(3 \mathrm{~min}$ at $3000 \mathrm{~g})$. The cells were then incubated at room temperature for $1 \mathrm{~h}$ in either deionized water (fully hemolysed control), in PBS, or with capsid in PBS. After centrifugation at $10000 \mathrm{~g}$ for $5 \mathrm{~min}$, the supernatant was separated from the pellet, and the absorbance was measured at $550 \mathrm{~nm}$ using a SpectraMax i3x Multi-Mode microplate reader (Molecular Devices). Absorbance of the suspension treated with deionized water defined complete hemolysis. All tests were done in triplicate, and results are shown in Table S1. The values given correspond to concentrations needed to kill half of the sample population (50\% lysis of erythrocytes) and are expressed as median lethal concentrations, $\mathrm{LC}_{50}$.

Bacterial Culture for Single-Cell Antimicrobial Kinetics Measurements. Lysogeny broth (LB) $(10 \mathrm{~g} / \mathrm{L}$ tryptone, $5 \mathrm{~g} / \mathrm{L}$ yeast extract, and $0.5 \mathrm{~g} / \mathrm{L} \mathrm{NaCl}$, Formedium) and $\mathrm{LB}$ agar plates ( $\mathrm{LB}$ with $15 \mathrm{~g} / \mathrm{L}$ agar) were used for planktonic and plate bacteria growth, respectively. E. coli BW25113 was purchased from Dharmacon (GE Healthcare). Single colonies were picked from a streak plate and were incubated at $37^{\circ} \mathrm{C}$, over $17 \mathrm{~h}$ in fresh $\mathrm{LB}$ medium $(100 \mathrm{~mL})$ with shaking $(200 \mathrm{rpm})$. The prepared culture was spun down $(10 \mathrm{~min}$, $3000 \mathrm{~g}$, and $20{ }^{\circ} \mathrm{C}$ ). The supernatant was filtered twice (Medical Millex-GS filter, $0.22 \mu \mathrm{m}$, Millipore Corp.) and used to resuspend the bacteria pellet to an $\mathrm{OD}_{595}$ of 50 . The resulting highly concentrated bacterial suspension was used in high-throughput single-cell kinetic measurements, together with $\mathrm{M} 9$ minimal medium $\left(7 \mathrm{~g} / \mathrm{L} \mathrm{Na}_{2} \mathrm{HPO}_{4}\right.$, $3 \mathrm{~g} / \mathrm{L} \mathrm{KH}_{2} \mathrm{PO}_{4}, 1 \mathrm{~g} / \mathrm{L} \mathrm{NH} \mathrm{NH}_{4} \mathrm{Cl}, 0.5 \mathrm{~g} / \mathrm{L} \mathrm{NaCl}, 1 \mathrm{mM}$ thiamine hydrochloride) (Sigma-Aldrich), ampicillin (Sigma-Aldrich), and propidium iodide (PI) (Thermo Fisher Scientific), as described below.

High-Throughput Single-Cell Kinetic Measurements. Antimicrobial efficacy with a single-cell resolution was measured using a multichannel microfluidics device as reported elsewhere. ${ }^{44,45}$ The device used was a polydimethylsiloxane (PDMS, Dow Corning) replica of the original mold kindly provided by Suckjoon Jun. ${ }^{44}$ The device is an array of dead-end microfluidic channels $1.5 \mu \mathrm{m}$ in diameter and $25 \mu \mathrm{m}$ in length. Each channel can host 1-4 bacterial cells in a single file. The channels are connected to a main microchamber $(25 \times 100 \mu \mathrm{m})$ that is continuously supplied with antimicrobial agents, fresh LB, or PI (see below). The device was permanently attached to a glass coverslip and functionalized with a solution of bovine serum albumin $(50 \mathrm{mg} / \mathrm{mL})$. A $2 \mu \mathrm{L}$ amount of the highly concentrated bacterial suspension, prepared as described above, was injected in the device, and individual bacteria were allowed to diffuse into the lateral channels for $30 \mathrm{~min}$. The device was then completed with fluorinated ethylene propylene inlet and outlet tubing $(1 / 32$ in. $\times 0.008$ in.) connected to a flow-rate measuring system (Flow Unit S, Fluigent, France) with the applied pressure controlled by a computerized pressure-based flow control system (MFCS-4C, Fluigent). The completed device was mounted on an inverted microscope (IX73 Olympus, Tokyo, Japan) equipped with a $60 \times, 1.2$ NA objective (UPLSAPO60XW, Olympus) and an sCMOS camera (Zyla 4.2, Andor, Belfast, UK) used to acquire bright-field images (exposure time $0.03 \mathrm{~s}$ ) of a thousand channels per hour for the duration of each experiment $(24 \mathrm{~h})$. After acquiring the first set of images, the microfluidic environment was changed by flowing M9LB (9:1 v/v) containing antimicrobial agents (D/ $\Psi$-capsids or ampicillin) at $25 \times$ MIC at $100 \mu \mathrm{L} / \mathrm{h}$ over $3 \mathrm{~h}$ and then by LB for a further $21 \mathrm{~h}$. At $24 \mathrm{~h}$ PI $(30 \mu \mathrm{M})$ was delivered into the microfluidic device for $10 \mathrm{~min}$ to identify dead cells with compromised cell membranes. The device allowed tracking each bacterial cell and its progeny throughout the assay, with the images obtained in each channel loaded to ImageJ.

Time-Lapse Structured Illumination Microscopy of E. coli and S. aureus. Bacteria (E. coli ATCC 15597 and S. aureus ATCC 6538 ) were inoculated into Mueller Hinton broth, grown overnight at $37^{\circ} \mathrm{C}$ and $150 \mathrm{rpm}$, reinoculated, and grown to an $\mathrm{OD}_{600}$ of $0.5-0.8$. The cells were then pelleted by centrifugation (4000 rpm, $10 \mathrm{~min}$ ) and, after removing the supernatant, were resuspended in $1 \mathrm{~mL}$ of PBS $(10 \mathrm{mM})$ and transferred to an Eppendorf tube. FM4-64 (1 mg/ $\mathrm{mL}, 5 \mu \mathrm{L})$ was added to each tube followed by rotation on a rotating disk for $5 \mathrm{~min}$. The cells were then centrifuged $(7000 \mathrm{rpm}, 3 \mathrm{~min})$, the supernatant was removed, and the cell pellet was resuspended in PBS $(1 \mathrm{~mL})$. Bacteria was then diluted to an $\mathrm{OD}_{600}$ of 0.16 and 0.08 for $E$. coli and S. aureus, respectively. A $100 \mu \mathrm{L}$ amount of each suspension was added to different wells of a chambered microscope coverslip (Ibidi $\mu$-Slide 8 well) and left for $30 \mathrm{~min}$ to allow cells to settle onto the substrate. Immediately prior to each imaging experiment a $100 \mu \mathrm{L}$ solution of $\Psi$-capsids assembled from carboxyfluorescein-labeled and unlabeled triskelions at 1:100 molar ratios was added to the well to a final concentration of $50 \mu \mathrm{M}$ (total peptide). For control data sets, $100 \mu \mathrm{L}$ of PBS was added prior to imaging. Time lapse imaging was performed at $5 \mathrm{~min}$ intervals using a custom-built structured illumination microscope. ${ }^{54}$ Briefly, sinusoidal excitation patterns were generated by projecting a spatially filtered image of a spatial light modulator (SLM), configured to display a series of binary phase gratings, into the focal plane of the microscope objective lens (UPLSAPO $60 \times / 1.3$, Olympus). Sample images were acquired using a scientific CMOS camera (ORCA-Flash4.0, Hamamatsu Photonics), with the global exposure period of the camera's rolling shutter synchronized to the pattern displayed on the SLM. At each time point FM4-64 and carboxyfluorescein-labeled capsids were imaged sequentially, using excitation at $561 \mathrm{~nm}$ with a $655 \mathrm{~nm}$ long-pass emission filter and excitation at $488 \mathrm{~nm}$ with a $525 / 50$ bandpass emission filter, respectively. Images were reconstructed as described elsewhere, ${ }^{55}$ and lateral drift and chromatic offsets in the reconstructed images were corrected using ImageJ. The FM4-64 color channel was then corrected for photobleaching using an exponential fit to the image intensity within a suitable region of interest. Manual background subtraction and color balancing were performed to optimize image contrast.

In Vivo MRSA Clearance Assay. The Galleria mellonella larvae assay was performed as described elsewhere. ${ }^{57,58}$ Wax moth larvae were purchased in bulk from Livefood UK, stored at $4{ }^{\circ} \mathrm{C}$ upon arrival, and kept at $37{ }^{\circ} \mathrm{C}$ during the course of the assay. $\Psi$-Capsid samples were prepared from stock solutions in Milli- $Q$ water to working concentrations in sterile PBS. Typically, a single bacterial colony was picked to inoculate $5 \mathrm{~mL}$ of tryptic soy broth (TSB), and the resulting culture was left to grow overnight $(\sim 16 \mathrm{~h})$ at $37^{\circ} \mathrm{C}$ with shaking $(200 \mathrm{rpm})$. The culture was then diluted $(100 \times)$ into fresh TSB $(5 \mathrm{~mL})$ and incubated over $4 \mathrm{~h}$ at $37^{\circ} \mathrm{C}$ with shaking $(200 \mathrm{rpm})$. After centrifugation $(2500 \mathrm{~g})$ for $10 \mathrm{~min}$, pellets were obtained and resuspended in sterile PBS to an $\mathrm{OD}_{595}$ of 0.2 , giving $\sim 10^{8} \mathrm{CFU} / \mathrm{mL}$. The resuspended culture $\left(10 \mu \mathrm{L}\right.$ aliquots; $\left.\sim 1.2 \times 10^{6} \mathrm{CFU}\right)$ was administered to larvae (seven groups; $n=10$ in each group) behind the rear thoracic segments using a Tridak stepper pipette dispenser (Dymax, UK). The infected larvae were then treated by injection with $10 \mu \mathrm{L}$ of $\mathrm{L} / \Psi$-capsid $(12.5 \mu \mathrm{M}), \mathrm{D} / \Psi$-capsid, $(12.5 \mu \mathrm{M})$, magainin 2 $(12.5 \mu \mathrm{M})$, cecropin B $(12.5 \mu \mathrm{M}), \operatorname{LL} 37(12.5 \mu \mathrm{M})$, vancomycin $(40$ $\mu \mathrm{M})$, or PBS at stated time points after inoculation. The toxicity of $\Psi$ capsid was assessed using two groups of larvae ( $n=10$ in each group). These were mock-infected with PBS and treated with $10 \mu \mathrm{L}$ of $\mathrm{L}$ or D/ $\Psi$-capsid $(25 \mu \mathrm{M})$ at stated time points after inoculation. For the delayed treatment assay, three groups of infected larvae $\left(\sim 10^{6} \mathrm{CFU}\right)$ were treated with $10 \mu \mathrm{L}$ of $\mathrm{L} / \Psi$-capsid $(12.5 \mu \mathrm{M})$, vancomycin $(40$ 
$\mu \mathrm{M})$, or PBS at stated time points after inoculation. All experiments were carried out as blind studies, and the treatment identities were not revealed until each experiment was completed. Larvae were considered dead when they did not respond to touch to the head. Survival curves were generated and analyzed using GraphPad Prism 6 software.

\section{ASSOCIATED CONTENT}

\section{S Supporting Information}

The Supporting Information is available free of charge at https://pubs.acs.org/doi/10.1021/acsnano.9b06814.

Biological activities of pseudocapsids and other antimicrobial agents used for comparison; RP-HPLC profiles and MALDI-ToF spectra for triskelions and peptides used in the study; $\mathrm{MD}$ simulations and molecular models for pseudocapsids; CD and FT-IR spectra for pseudocapsid folding; fluorescence microscopy and TEM images (PDF)

Movie as described in the text (MOV)

Movie as described in the text (MOV)

Movie as described in the text (MOV)

Movie as described in the text (MP4)

Movie as described in the text (MP4)

\section{AUTHOR INFORMATION}

\section{Corresponding Author}

*Fax: (+44) 20 86140573. Tel: (+44) 20 89436078. E-mail: max.ryadnov@npl.co.uk.

\section{ORCID $\odot$}

Ibolya E. Kepiro: 0000-0002-8934-3389

Irene Marzuoli: 0000-0001-7536-6144

Katharine Hammond: 0000-0002-3755-6489

Xiaoliang Ba: 0000-0002-3882-3585

Helen Lewis: 0000-0002-9993-0640

Michael Shaw: 0000-0001-6099-3217

Smita B. Gunnoo: 0000-0002-7435-8377

Emiliana De Santis: 0000-0002-0943-6586

Urszula Łapińska: 0000-0003-3593-9248

Stefano Pagliara: 0000-0001-9796-1956

Mark A. Holmes: 0000-0002-5454-1625

Christian D. Lorenz: 0000-0003-1028-4804

Bart W. Hoogenboom: 0000-0002-8882-4324

Franca Fraternali: 0000-0002-3143-6574

Maxim G. Ryadnov: 0000-0003-4847-1154

\section{Author Contributions}

OI.E.K. and I.M. contributed equally to this work.

\section{Notes}

The authors declare no competing financial interest.

\section{ACKNOWLEDGMENTS}

We acknowledge funding from the UK's Department for Business, Energy and Industrial Strategy, from the UK's Medical Research Council P2D grant MCPC17189 (to U.L. and S.P.), and from Engineering and Physical Sciences Research Council (EPSRC) grant EP/M028100/1 (to B.W.H.). The work used the ARCHER UK National Supercomputing Service and the UK Materials and Molecular Modelling Hub (MMM Hub) for computational resources, which is partially funded by EPSRC (EP/P020194/1). The access was provided by the UK's HEC Materials Chemistry Consortium (via C.D.L.), which is funded by EPSRC (EP/
L000202). We also acknowledge the EPSRC Centre for Doctoral Training in Cross-Disciplinary Approaches to NonEquilibrium Systems (EP/L015854/1). We thank Dr. Pascale Schellenberger for support in acquiring the TEM images of MS2 bacteriophages.

\section{REFERENCES}

(1) Podolsky, S. H. The Evolving Response to Antibiotic Resistance (1945-2018). Palgrave Commun. 2018, 4, 124.

(2) Tacconelli, E.; Carrara, E.; Savoldi, A.; Harbarth, S.; Mendelson, M.; Monnet, D. L.; Pulcini, C.; Kahlmeter, G.; Kluytmans, J.; Carmeli, Y.; et al. Discovery, Research, and Development of New Antibiotics: The WHO Priority List of Antibiotic-Resistant Bacteria and Tuberculosis. Lancet Infect. Dis. 2018, 18, 318-327.

(3) Laxminarayan, R.; Matsoso, P.; Pant, S.; Brower, C.; Røttingen, J. A.; Klugman, K.; Davies, S. Access to Effective Antimicrobials: A Worldwide Challenge. Lancet 2016, 387, 168-175.

(4) Coates, A.; Hu, Y.; Bax, R.; Page, C. The Future Challenges Facing the Development of New Antimicrobial Drugs. Nat. Rev. Drug Discovery 2002, 1, 895-910.

(5) Haney, E. F.; Straus, S. K.; Hancock, R. E. W. Reassessing the Host Defense Peptide Landscape. Front. Chem. 2019, 7, 43.

(6) Hancock, R. E.; Sahl, H.-G. Antimicrobial and Host-Defense Peptides as New Anti-Infective Therapeutic Strategies. Nat. Biotechnol. 2006, 24, 1551-1557.

(7) Shai, Y. Mode of Action of Membrane Active Antimicrobial Peptides. Biopolymers 2002, 66, 236-248.

(8) Wang, G. Human Antimicrobial Peptides and Proteins. Pharmaceuticals 2014, 7, 545-594.

(9) Telang, S. Lactoferrin: A Critical Player in Neonatal Host Defense. Nutrients 2018, 10, 1228.

(10) Hunter, H. N.; Demcoe, A. R.; Jenssen, H.; Gutteberg, T. J.; Vogel, H. J. Human Lactoferricin is Partially Folded in Aqueous Solution and is Better Stabilized in a Membrane Mimetic Solvent. Antimicrob. Agents Chemother. 2005, 49, 3387-3395.

(11) Castelletto, V.; De Santis, E.; Alkassem, H.; Lamarre, B.; Noble, J. E.; Ray, S.; Bella, A.; Burns, J. R.; Hoogenboom, B. W.; Ryadnov, M. G. Structurally Plastic Peptide Capsules for Synthetic Antimicrobial Viruses. Chem. Sci. 2016, 7, 1707-1711.

(12) Krauzewicz, N.; Stokrová, J.; Jenkins, C.; Elliott, M.; Higgins, C. F.; Griffin, B. E. Virus-Like Gene Transfer into Cells Mediated by Polyoma Virus Pseudocapsids. Gene Ther. 2000, 7, 2122-2131.

(13) Saugar, I.; Luque, D.; Oña, A.; Rodríguez, J. F.; Carrascosa, J. L.; Trus, B. L.; Castón, J. R. Structural Polymorphism of the Major Capsid Protein of a Double-Stranded RNA Virus: An Amphipathic Alpha Helix as a Molecular Switch. Structure 2005, 13, 1007-1017.

(14) Bajaj, S.; Banerjee, M. In Vitro Assembly of Polymorphic VirusLike Particles from the Capsid Protein of a Nodavirus. Virology 2016, 496, 106-115.

(15) Uppalapati, M.; Lee, D. J.; Mandal, K.; Li, H.; Miranda, L. P.; Lowitz, J.; Kenney, J.; Adams, J. J.; Ault-Riché, D.; Kent, S. B.; et al. A Potent D-Protein Antagonist of VEGF-A is Nonimmunogenic, Metabolically Stable, and Longer-Circulating In Vivo. ACS Chem. Biol. 2016, 11, 1058-1065.

(16) Arranz-Gibert, P.; Ciudad, S.; Seco, J.; Garcia, J.; Giralt, E.; Teixido, M. Immunosilencing Peptides by Stereochemical Inversion and Sequence Reversal: Retro-D-Peptides. Sci. Rep. 2018, 8, 6446.

(17) Ryadnov, M. G.; Degtyareva, O. V.; Kashparov, I. A.; Mitin, Y. V. A New Synthetic All-D-Peptide with High Bacterial and Low Mammalian Cytotoxicity. Peptides 2002, 23, 1869-1871.

(18) King, T. P.; Wade, D.; Coscia, M. R.; Mitchell, S.; Kochoumian, L.; Merrifield, B. Structure-Immunogenicity Relationship of Melittin, Its Transposed Analogues, and D-Melittin. J. Immunol. 1994, 153, 1124-1131.

(19) Bland, J. M.; De Lucca, A. J.; Jacks, T. J.; Vigo, C. B. All-DCecropin B: Synthesis, Conformation, Lipopolysaccharide Binding, and Antibacterial Activity. Mol. Cell. Biochem. 2001, 218, 105-111. 
(20) García-Montoya, I. A.; Cendón, T. S.; Arévalo-Gallegos, S.; Rascón-Cruz, Q. Lactoferrin a Multiple Bioactive Protein: An Overview. Biochim. Biophys. Acta, Gen. Subj. 2012, 1820, 226-236.

(21) Zhao, X. Y.; Hutchens, T. W. Proposed Mechanisms for the Involvement of Lactoferrin in the Hydrolysis of Nucleic Acids. Adv. Exp. Med. Biol. 1994, 357, 271-278.

(22) Sallmann, F. R.; Baveye-Descamps, S.; Pattus, F.; Salmon, V.; Branza, N.; Spik, G.; Legrand, D. Porins OmpC and PhoE of Escherichia Coli as Specific Cell-Surface Targets of Human Lactoferrin. Binding Characteristics and Biological Effects. J. Biol. Chem. 1999, 274, 16107-16114.

(23) Schibli, D. J.; Hwang, P. M.; Vogel, H. J. The Structure of the Antimicrobial Active Center of Lactoferricin B Bound to Sodium Dodecyl Sulfate Micelles. FEBS Lett. 1999, 446, 213-217.

(24) Cochran, A. G.; Skelton, N. J.; Starovasnik, M. A. Tryptophan Zippers: Stable, Monomeric Beta-Hairpins. Proc. Natl. Acad. Sci. U. S. A. 2001, 98, 5578-5583.

(25) Venkataram Prasad, B. V.; Schmid, M. F. Principles of Virus Structural Organization. Adv. Exp. Med. Biol. 2012, 726, 17-47.

(26) Kirchhausen, T. Clathrin. Annu. Rev. Biochem. 2000, 69, 699727.

(27) Matsuura, K. Synthetic Approaches to Construct Viral CapsidLike Spherical Nanomaterials. Chem. Commun. (Cambridge, U. K.) 2018, 54, 8944-8959.

(28) Fletcher, J. M.; Harniman, R. L.; Barnes, F. R.; Boyle, A. L.; Collins, A.; Mantell, J.; Sharp, T. H.; Antognozzi, M.; Booth, P. J.; Linden, N.; et al. Self-Assembling Cages from Coiled-Coil Peptide Modules. Science 2013, 340, 595-599.

(29) Mannige, R. V.; Brooks, C. L., 3rd. Periodic Table of Virus Capsids: Implications for Natural Selection and Design. PLoS One 2010, 5, No. e9423.

(30) Schein, S.; Gayed, J. M. Fourth Class of Convex Equilateral Polyhedron with Polyhedral Symmetry Related to Fullerenes and Viruses. Proc. Natl. Acad. Sci. U. S. A. 2014, 111, 2920-2925.

(31) Holowka, E. P.; Sun, V. Z.; Kamei, D. T.; Deming, T. J. Polyarginine Segments in Block Copolypeptides Drive both Vesicular Assembly and Intracellular Delivery. Nat. Mater. 2007, 6, 52-57.

(32) Monticelli, L.; Kandasamy, S. K.; Periole, X.; Larson, R. G.; Tieleman, D. P.; Marrink, S. J. The MARTINI Coarse-Grained Force Field: Extension to Proteins. J. Chem. Theory Comput. 2008, 4, 819834.

(33) Oostenbrink, C.; Villa, A.; Mark, A.; Van Gunsteren, W. A Biomolecular Force Field Based on the Free Enthalpy of Hydration and Solvation: The GROMOS Force-Field Parameter Sets 53A5 and 53A6. J. Comput. Chem. 2004, 25, 1656-1676.

(34) Matsuura, K.; Watanabe, K.; Matsuzaki, T.; Sakurai, K.; Kimizuka, N. Self-Assembled Synthetic Viral Capsids from a 24-mer Viral Peptide Fragment. Angew. Chem., Int. Ed. 2010, 49, 9662-9665.

(35) Minten, I. J.; Hendriks, L. J.; Nolte, R. J.; Cornelissen, J. J. Controlled Encapsulation of Multiple Proteins in Virus Capsids. J. Am. Chem. Soc. 2009, 131, 17771-17773.

(36) Derjaguin, B. V.; Muller, V. M.; Toropov, Yu. P. Effect of Contact Deformations on the Adhesion of Particles. J. Colloid Interface Sci. 1975, 53, 314-326.

(37) Glasgow, J.; Tullman-Ercek, D. Production and Applications of Engineered Viral Capsids. Appl. Microbiol. Biotechnol. 2014, 98, $5847-5858$.

(38) Maassen, S. J.; van der Ham, A. M.; Cornelissen, J. L. M. Combining Protein Cages and Polymers: From Understanding SelfAssembly to Functional Materials. ACS Macro Lett. 2016, 5, 987-994.

(39) Noble, J. E.; De Santis, E.; Ravi, J.; Lamarre, B.; Castelletto, V.; Mantell, J.; Ray, S.; Ryadnov, M. G. A De Novo Virus-Like Topology for Synthetic Virions. J. Am. Chem. Soc. 2016, 138, 12202-12210.

(40) Johnson, J. E. Functional Implications of Protein-Protein Interactions in Icosahedral Viruses. Proc. Natl. Acad. Sci. U. S. A. 1996, 93, 27-33.

(41) Speir, J. A.; Bothner, B.; Qu, C.; Willits, D. A.; Young, M. J.; Johnson, J. E. Enhanced Local Symmetry Interactions Globally
Stabilize a Mutant Virus Capsid that Maintains Infectivity and Capsid Dynamics. J. Virol. 2006, 80, 3582-3591.

(42) Li, S.; Roy, P.; Travesset, A.; Zandi, R. Why Large Icosahedral Viruses Need Scaffolding Proteins. Proc. Natl. Acad. Sci. U. S. A. 2018, 115, 10971-10976.

(43) Rakowska, P. D.; Jiang, H.; Ray, S.; Pyne, A.; Lamarre, B.; Carr, M.; Judge, P. J.; Ravi, J.; Gerling, U. I.; Koksch, B.; et al. Nanoscale Imaging Reveals Laterally Expanding Antimicrobial Pores in Lipid Bilayers. Proc. Natl. Acad. Sci. U. S. A. 2013, 110, 8918-8923.

(44) Pyne, A.; Pfeil, M. P.; Bennett, I.; Ravi, J.; Iavicoli, P.; Lamarre, B.; Roethke, A.; Ray, S.; Jiang, H.; Bella, A.; et al. Engineering Monolayer Poration for Rapid Exfoliation of Microbial Membranes. Chem. Sci. 2017, 8, 1105-1115.

(45) Martínez, L.; Andrade, R.; Birgin, E. G.; Martínez, J. M. Packmol: A Package for Building Initial Configurations for Molecular Dynamics Simulations. J. Comput. Chem. 2009, 30, 2157-2164.

(46) Wang, P.; Robert, L.; Pelletier, J.; Dang, W. L.; Taddei, F.; Wright, A.; Jun, S. Robust Growth of Escherichia Coli. Curr. Biol. 2010, 20, 1099-1103.

(47) Pagliara, S.; Chimerel, C.; Langford, R.; Aarts, D. G.; Keyser, U. F. Parallel Sub-Micrometre Channels with Different Dimensions for Laser Scattering Detection. Lab Chip 2011, 11, 3365-3368.

(48) Bamford, R. A.; Smith, A.; Metz, J.; Glover, G.; Titball, R. W.; Pagliara, S. Investigating the Physiology of Viable but Non-Culturable Bacteria by Microfluidics and Time-Lapse Microscopy. BMC Biol. 2017, 15, 121.

(49) Balaban, N. Q.; Helaine, S.; Lewis, K.; Ackermann, M.; Aldridge, B.; Andersson, D. I.; Brynildsen, M. P.; Bumann, D.; Camilli, A.; Collins, J. J.; et al. Definitions and Guidelines for Research on Antibiotic Persistence. Nat. Rev. Microbiol. 2019, 17, 441-448.

(50) Zhang, Y. Persisters, Persistent Infections and the Yin-Yang Model. Emerging Microbes Infect. 2014, 3, No. e3.

(51) Ayrapetyan, M.; Williams, T. C.; Oliver, J. D. Bridging the Gap between Viable but Non-Culturable and Antibiotic Persistent Bacteria. Trends Microbiol. 2015, 23, 7-13.

(52) Stapels, D. A. C.; Hill, P. W. S.; Westermann, A. J.; Fisher, R. A.; Thurston, T. L.; Saliba, A. E.; Blommestein, I.; Vogel, J.; Helaine, S. Salmonella Persisters Undermine Host Immune Defenses during Antibiotic Treatment. Science 2018, 362, 1156-1160.

(53) Schindler, P. R.; Teuber, M. Action of Polymyxin B on Bacterial Membranes: Morphological Changes in the Cytoplasm and in the Outer Membrane of Salmonella Typhimurium and Escherichia Coli B. Antimicrob. Agents Chemother. 1975, 8, 95-104.

(54) Edgar, R.; Rokney, A.; Feeney, M.; Semsey, S.; Kessel, M.; Goldberg, M. B.; Adhya, S.; Oppenheim, A. B. Bacteriophage Infection is Targeted to Cellular Poles. Mol. Microbiol. 2008, 68, $1107-1116$

(55) Hu, B.; Margolin, W.; Molineux, I. J.; Liu, J. Structural Remodeling of Bacteriophage $\mathrm{T} 4$ and Host Membranes during Infection Initiation. Proc. Natl. Acad. Sci. U. S. A. 2015, 112, E4919E4928.

(56) Shaw, M.; Zajiczek, L.; O'Holleran, K. High Speed Structured Illumination Microscopy in Optically Thick Samples. Methods 2015, $88,11-19$.

(57) O’Holleran, K.; Shaw, M. Optimized Approaches for Optical Sectioning and Resolution Enhancement in 2D Structured Illumination Microscopy. Biomed. Opt. Express 2014, 5, 2580-2590.

(58) Shaw, M.; Bella, A.; Ryadnov, M. G. CREIM: Coffee Ring Effect Imaging Model for Monitoring Protein Self-Assembly In Situ. J. Phys. Chem. Lett. 2017, 8, 4846-4851.

(59) Desbois, A. P.; Coote, P. J. Wax Moth Larva (Galleria mellonella): An In Vivo Model for Assessing the Efficacy of Antistaphylococcal Agents. J. Antimicrob. Chemother. 2011, 66, $1785-1790$

(60) Ba, X.; Harrison, E. M.; Lovering, A. L.; Gleadall, N.; Zadoks, R.; Parkhill, J.; Peacock, S. J.; Holden, M. T.; Paterson, G. K.; Holmes, M. A. Old Drugs to Treat Resistant Bugs: Methicillin-Resistant Staphylococcus Aureus Isolates with $\mathrm{mecC}$ are Susceptible to a 
Combination of Penicillin and Clavulanic Acid. Antimicrob. Agents Chemother. 2015, 59, 7396-7404.

(61) Gibreel, T. M.; Upton, M. Synthetic Epidermicin NI01 can Protect Galleria Mellonella Larvae from Infection with Staphylococcus Aureus. J. Antimicrob. Chemother. 2018, 68, 2269-2273.

(62) Takemura-Uchiyama, I.; Uchiyama, J.; Kato, S.; Inoue, T.; Ujihara, T.; Ohara, N.; Daibata, M.; Matsuzaki, S. Evaluating Efficacy of Bacteriophage Therapy against Staphylococcus Aureus Infections using a Silkworm Larval Infection Model. FEMS Microbiol. Lett. 2013, 347, 52-60.

(63) De Santis, E.; Alkassem, H.; Lamarre, B.; Faruqui, N.; Bella, A.; Noble, J. E.; Micale, N.; Ray, S.; Burns, J. R.; Yon, A. R.; et al. Antimicrobial Peptide Capsids of De Novo Design. Nat. Commun. 2017, 8, 2263.

(64) Matsuura, K. Construction of Spherical Virus-Inspired Peptide Nanoassemblies. Polym. J. 2012, 44, 469-474.

(65) Rossmann, M. G.; Arnold, E.; Erickson, J. W.; Frankenberger, E. A.; Griffith, J. P.; Hecht, H. J.; Johnson, J. E.; Kamer, G.; Luo, M.; Mosser, A. G.; et al. Structure of a Human Common Cold Virus and Functional Relationship to Other Picornaviruses. Nature 1985, 317, $145-153$.

(66) Tarasov, S. G.; Gaponenko, V.; Howard, O. M.; Chen, Y.; Oppenheim, J. J.; Dyba, M. A.; Subramaniam, S.; Lee, Y.; Michejda, C.; Tarasova, N. I. Structural Plasticity of a Transmembrane Peptide Allows Self-Assembly into Biologically Active Nanoparticles. Proc. Natl. Acad. Sci. U. S. A. 2011, 108, 9798-9803.

(67) Ryadnov, M. G. A Self-Assembling Peptide Polynanoreactor. Angew. Chem., Int. Ed. 2007, 46, 969-972.

(68) Papapostolou, D.; Smith, A. M.; Atkins, E. D.; Oliver, S. J.; Ryadnov, M. G.; Serpell, L. C.; Woolfson, D. N. Engineering Nanoscale Order into a Designed Fiber. Proc. Natl. Acad. Sci. U. S. A. 2007, 104, 10853-10858.

(69) Matsuura, K.; Murasato, K.; Kimizuka, N. Artificial Peptide Nanospheres Self-Assembled from Three-Way Junctions of $\beta$-SheetForming Peptides. J. Am. Chem. Soc. 2005, 127, 10148-10149.

(70) Brauner, A.; Fridman, O.; Gefen, O.; Balaban, N. Q. Distinguishing between Resistance, Tolerance and Persistence to Antibiotic Treatment. Nat. Rev. Microbiol. 2016, 14, 320-330.

(71) Neuhaus, F. C.; Baddiley, J. A Continuum of Charge: Structures and Functions of D-Alanyl-Teichoic Acids in GramPositive Bacteria. Microbiol. Mol. Biol. Rev. 2003, 67, 686-723.

(72) Needham, B. D.; Trent, M. S. Fortifying the Barrier: The Impact of Lipid A Remodeling on Bacterial Pathogenesis. Nat. Rev. Microbiol. 2013, 11, 467-481.

(73) Joo, H.-S.; Fu, C.-I.; Otto, M. Bacterial Strategies of Resistance to Antimicrobial Peptides. Philos. Trans. R. Soc., B 2016, 371, 20150292.

(74) Ryan, L.; Lamarre, B.; Diu, T.; Ravi, J.; Judge, P. J.; Temple, A.; Carr, M.; Cerasoli, E.; Su, B.; Jenkinson, H. F.; et al. AntiAntimicrobial Peptides: Folding-Mediated Host Defense Antagonists. J. Biol. Chem. 2013, 288, 20162-20172.

(75) Zasloff, M. Antimicrobial Peptides of Multicellular Organisms. Nature 2002, 415, 389-395.

(76) Lazar, V.; Martins, A.; Spohn, R.; Daruka, L.; Grézal, G.; Fekete, G.; Számel, M.; Jangir, P. K.; Kintses, B.; Csörgő, B.; et al. Antibiotic-Resistant Bacteria Show Widespread Collateral Sensitivity to Antimicrobial Peptides. Nat. Microbiol. 2018, 3, 718-731.

(77) Pfeil, M. P.; Pyne, A. L. B.; Losasso, V.; Ravi, J.; Lamarre, B.; Faruqui, N.; Alkassem, H.; Hammond, K.; Judge, P. J.; Winn, M.; et al. Tuneable Poration: Host Defense Peptides as Sequence Probes for Antimicrobial Mechanisms. Sci. Rep. 2018, 8, 14926. 